\title{
Rice husk silica for the stabilization of food-grade oil-in-water (O/W) emulsions
}

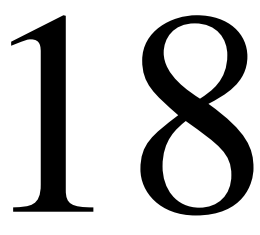

Lanny Sapei

Department of Chemical Engineering, University of Surabaya, Raya Kalirungkut, Surabaya, East Java, Indonesia

\section{Introduction}

Food is a basic essential for human beings. Therefore, the overall product quality such as nutrition, texture, appearance, taste, and stability are of fundamental considerations. To provide food with good stability along with desirable texture and appearance, stabilizers have been usually added into processed food products. Stabilizers are generally added into processed foods containing mixtures of aqueous and oil phases. It functions as an enhancement to food texture and appearance, since it helps produce a stable emulsion. Emulsifiers are among the stabilizers which promptly enhance the stability of water-in-oil (W/O) or oil-in-water $(\mathrm{O} / \mathrm{W})$ emulsion-based food products. Emulsifiers consist of polar heads and nonpolar tails, and they reorient themselves on the interface of oil and water emulsion to lower the surface tension arising between those two immiscible phases, thus enabling the stable dispersion of one phase into another.

Natural emulsifiers have been replaced by synthetic ones for a long time since they can be mass produced and are therefore lower in price. However, there has in recent times been a growing popularity in natural emulsifiers due to the undesirable health effects of synthetic emulsifiers over the longterm such as obesity and related issues (Simmons et al., 2014). On the other hand, natural emulsifiers have low toxicity, are easily degradable, biodegradable, are effective in extreme conditions, and are able to be reused via regeneration, so that they enjoy preference in the food industry despite their higher price (Koglin et al., 2010).

Solid particles have existed in emulsion formulation for many years, such as those used in the food, oil, pharmaceutical, and agrochemical industries (Binks, 2002). They are believed to enhance stability to some extent. In many food and foam emulsions stabilized mainly through proteins and phospholipids, solid particles play a significant role for necessary stabilization, such as ice crystals in ice cream and the particles of fat in whipping cream (Binks, 2002). The use of colloidal particles to stabilize emulsions and foams known as the Pickering emulsion has been known for at least a century (Aveyard et al., 2003). Ramsden (1903) concluded that the existence of viscous material at the two immiscible liquids' interfaces contributed, in part, to the stability of many emulsions.

Solid and stabilized emulsion was formed, thanks to finely divided solids dispersed between the interfaces of oil and water. Pickering (1907) observed that colloid particles dampened more easily by 
water than by oil could more likely stabilize O/W emulsions. However, the Pickering emulsion has been slowed down, a slow development until the 1980s (Dyab, 2012). Since then, along with progress in the characterization techniques of colloidal particles, there has been renewed interest in Pickering emulsions. Solid particles like metal sulfates, hydroxides, alumina, carbon, and iron oxide have been used as stabilizers of O/W or W/O emulsions (Binks, 2002; Wang et al., 2004; Dyab, 2012; Xie et al., 2018). Recently, some other solids such as hydroxyapatite (Hap), magnetic nanoparticles, chitosan (CS), nanotube, cyclodextrin (CD), and some food-grade stabilizers and organic particles can effectively serve as Pickering emulsifiers (Yang et al., 2017; Dai et al., 2018a, 2018b). Therefore, the applications of Pickering emulsions have become very widespread, for example, as porous scaffolds, catalysts, stimuli-responsive materials, delivery vehicles, and so on (Yang et al., 2017). Pickering emulsions have drawn significant research interest as templates in many fields due to the following advantages: (i) solid particles minimize droplet coalescences and bring about higher emulsion stability; (ii) many solid particles bestow materials with preferred traits such as porosity, responsiveness, etc; and (iii) some solid food-grade particles possess reduced toxicity, making them safer to use in vivo (Yang et al., 2017).

There are many behavior similarities of small solid particles and emulsifier molecules at the liquids' interfaces. Colloidal particles show similar behavior like surfactant molecules, especially when accumulated at the interfaces due to their partitioning between the immiscible liquids, rendering the stability to the emulsion. Solid particles likewise surfactants or emulsifiers tend to be adsorbed on the interface between two phases since they possess hydrophilic portions as well as hydrophobic portions. The tendency of an emulsifier toward oil or water liking is reflected by the term hydrophile-lipophile balance number, which is equivalent with the term wettability and contact angle for a spherical particle (Binks, 2002). It is well known that low molar mass emulsifiers and surface-active polymers can help diffuse powdered materials in a liquid by forming aggregated structures in liquid media. In contrast to emulsifiers, individual solid particles do not form aggregates such as micelle, therefore solubilization phenomena is not seen in the particle case. Spherical particles just simply adsorb to oil-water interfaces depending on the contact angle $\theta$ which governs the particles' wettability. The wetting efficiency of the solid by one liquid is likely greater than that of the other, leading to the weaker wetting liquid becomes the dispersed phase. For hydrophilic particles, e.g., metal oxides and silica, the particle surface stays more in water than in the oil phase and $\theta$ measured is normally less than $90^{\circ}$. For hydrophobic particles such as modified silica and carbon, the particle stays more in oil than in water and $\theta$ measured is generally greater than $90^{\circ}$ (Binks, 2002; Aveyard et al., 2003). Colloidal particles could effectively stabilize emulsions if they were wetted in partial by both aqueous and oil phases, thereby considered to be an important group of emulsifying agents (Tambe \& Sharma, 1993). Water-wet particles or hydrophilic solid particles tend to stabilize $\mathrm{O} / \mathrm{W}$ emulsions, while oil-wet particles or hydrophobic solid particles tend to stabilize W/O emulsions (Binks, 2002; Aveyard et al., 2003). The emulsion-stabilizing efficiency of these solids depends on such things as interparticle interactions, particle size, and particle wettability. Furthermore, the stability and type of emulsions formed depends on particle concentration, wettability, $\mathrm{pH}$ of the aqueous phase, the presence of ions in the aqueous phase, and the concentration and type of emulsifier present in the system (Tambe \& Sharma, 1993). Particles used for emulsion stabilization are normally submicrometer to a few micrometers in size (Tambe \& Sharma, 1993). Each particle size should be smaller than the emulsion droplets themselves for the particles to properly cover the droplets. The particle interaction at some degree especially between particles at the interface is necessary for an effective stabilization. From gathered evidence, in 
some systems it seems that weak particle flocculation improves stability of the emulsion (Aveyard et al., 2003). Adjusting the $\mathrm{pH}$, salt concentration, and temperature can modify the wettability of the particle (Binks et al., 2006). The adsorption of certain surfactants can also change the particles' wettability and may occasionally lead to emulsion-phase inversion (Binks, 2002).

The solid particles' ability to steady the emulsions relates to the formation of the interfacial barrier which provides the steric hindrance to droplet-droplet fusion and the modification of the interfacial region's rheological properties due to the particulate presence. The particles can arrest the Ostwald ripening process in emulsions due to the resulting capillary effects and high desorption energy of the particles (Tcholakova et al., 2008). The formation of highly viscous and rigid films at the interface layer induced by colloidal particles such as clays, resins, asphaltenes, wax, and biopolymers apparently promote emulsion stability (Urdahl \& Sjöblom, 1995; Al-Sahhaf et al., 2009; Hong \& Fischer, 2016; Dai et al., 2018a; Lu et al., 2018; Li et al., 2019). The capacity for solid particles to diffuse and remain in the interfacial region in a state of mechanical equilibrium would also dictate its emulsionstabilizing capacity. The adsorbed solid particles at the interface would then form rigid layer that can sterically curb the fusion of dispersed droplets. For obtaining a stable emulsion, there should be a minimum concentration of particles to sufficiently form a dense layer of particles around the droplets and to modify the degree of interparticle interaction. A heavy layer of solid particles at interfacial layer would influence the capacity of the colloidal particles to stabilize emulsions. The interfacial rheological properties change as the surface concentration of particles increase, resulting in full surface coverages. The interfacial region will tend to demonstrate viscoelastic behavior when the concentration of particles becomes sufficiently high (Tambe \& Sharma, 1993). The displacement of the colloidal particles along the interface results in droplet coalescences leading to emulsion instability. The forming of a fixed protective interfacial film, with particular interfacial rheological characteristics, is of great value to the stability of these Pickering emulsions. Moreover, the huge free energy of adsorption for particles of moderate wettability $\left(50^{\circ}<\theta<130^{\circ}\right)$ leads to incredible stability for certain emulsions due to irreversible adsorption, in contrast to emulsifier molecules which are typically in rapid dynamic equilibrium between the bulk phases and the oil-water interface (Aveyard et al., 2003). These properties offer several possible advantages of particulate emulsifiers over conventional surfactant in providing greater stability against coalescence and a reduced rate and extent of creaming/ sedimentation due to the improved viscosity of the continuous phase (Binks, 2002; Aveyard et al., 2003; Binks et al., 2006). The high-level stability found in solid-stabilized emulsions greatly benefits the shelf life of formulas that include those (Binks, 2002).

The stability of the formed emulsions increases as emulsifiers are added to the system (Tambe \& Sharma, 1993). The wettability of the solids is modified by the presence of emulsifier in the system and most likely enhances the interparticle interaction too. Along with extra surfactant molecules comes an enhanced emulsification capacity, which may be due to an alteration in particle wettability that accompanies surfactant adsorption, thereby modifying the contact angle (Binks \& Whitby, 2005). The incorporation of cationic surfactant also enhanced emulsion stability. This is predominantly due to the adsorption of emulsifier molecules both at the interfaces between solid-liquid and liquid-liquid (Binks \& Whitby, 2005). The added emulsifier molecules are partitioned to the interface, and in most cases, colloidal particles would be adsorbed at the oil-water interface, rendering steric hindrance against droplet coalescences. The proceeding interfacial structure is therefore a combination of emulsifiers associated with colloidal particles which leads to long-term stable $\mathrm{O} / \mathrm{W}$ emulsion due to the very rigid film surrounding the oil droplets (Reger et al., 2011) and viscoelastic interfaces that increase 
the magnitude of steric hindrance and decrease the rate of film thinning between coalescing droplets (Tambe \& Sharma, 1995; Reger et al., 2012).

\section{Silica for stabilization of $\mathrm{O} / \mathrm{W}$ emulsion}

Silica or silicon dioxide $\left(\mathrm{SiO}_{2}\right)$ is omnipotent in nature consisting of $26 \%$ of the earth's crust (Martin, 2007) and is present in a crystalline form in nearly all the minerals rocks, clays, and sands on the earth. It belongs to the only inorganic polymer which is most often colorless to white and insoluble in water. The term "biosilica" used in this context referred to silica biopolymer which was accumulated in the living tissues such as rice husk and was isolated thereof. Biosilica is also found in silica-rich plants such as horsetail (Sapei et al., 2007, 2008), bamboo, and grass. In lower creatures such as diatoms and radiolarian, silica was mainly deposited in their cell walls. Biosilica is amorphous in nature and tends to be hydrophilic due to the presence of hydroxyl group on their surface as depicted in Fig. 18.1.

Silica has widespread industrial applications as an antifoaming agent, as an excipient in drugs and vitamins, as dough modifier, and as adsorbent to clarify beverage and as viscosity modifier (Martin, 2007). Silica is also among the additive for foods (E 551) and is typically used as an anticaking agent. Silica was reported to have many potential health benefits. Many evidences supported a beneficial role of silicon in collagen formation, improving bone, cartilage, and connective tissue structure, prevention of toxicity to the brain, and maintenance of blood vessel integrity (Martin, 2007). Silica is common in the typical human diet and largely considered safe. There is no observed adverse effect level of $50,000 \mathrm{ppm}(\mathrm{mg} / \mathrm{L})$ for dietary silica (Martin, 2007).

Biosilica accumulated in plants consisted of colloidal primary particles of about $2 \mathrm{~nm}$ (Sapei et al., 2007), and therefore it has a great potential to be used for stabilizing O/W emulsion by diffusing into the oil-water interfaces forming a rigid and densely packed silica particle layer. There were few publications related to biosilica for the stabilization of food-grade O/W emulsions. Sapei et al. (2017a; 2017b) has reported the kinetics of destabilization of O/W emulsion stabilized by rice husk silica

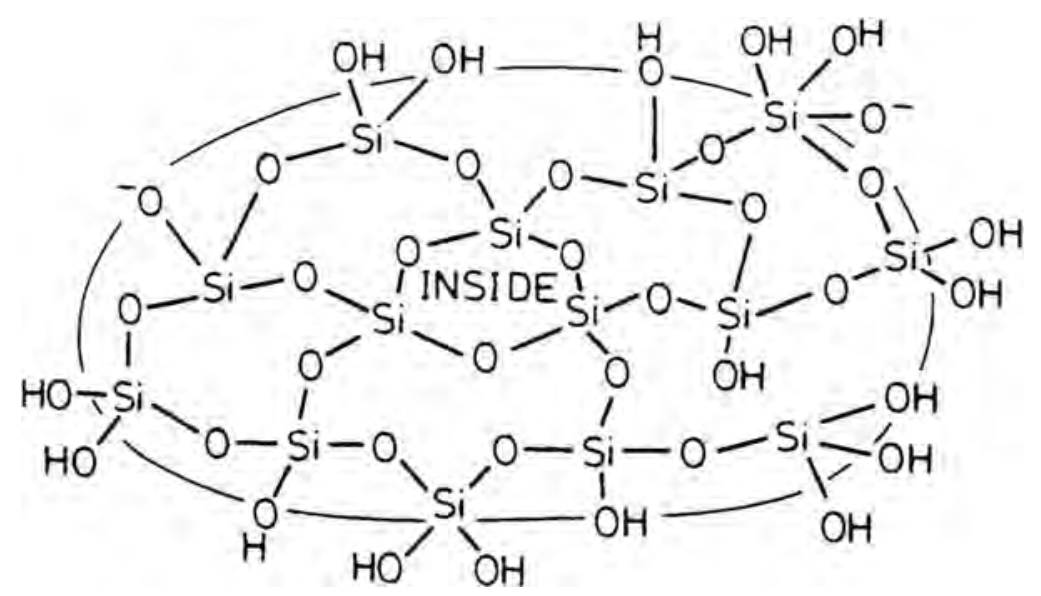

FIGURE 18.1

Schematic illustration of the nature of amorphous hydrated biosilica 
combined with lecithin and Tween-20. The destabilization rate of emulsions stabilized with biosilica and lecithin was reduced by $\sim 10 \%$ in comparison with the emulsions prepared without added emulsifiers (Sapei et al., 2017a). It seemed that the varying concentrations of both lecithin and silica slightly affected the destabilization rates of $\mathrm{O} / \mathrm{W}$ emulsions. The emulsion destabilization rate constant was reduced by $\sim 20 \%$ when the emulsion was stored at refrigerated temperatures (Sapei et al., 2017a). In the O/W emulsion stabilized with rice husk silica/Tween-20, it was demonstrated that the varying concentration of Tween-20 significantly influences the overall emulsion stability. The emulsion stability increased with the increase of Tween-20 concentration (Sapei et al., 2017b). The addition of Tween-20 could help increase the wettability of biosilica to be firmly attached on the interfaces, rendering the stability of the resulting Pickering emulsion. The instability of $\mathrm{O} / \mathrm{W}$ emulsion process due to mainly oil droplet coalescences followed the first-order kinetic model. Recent study demonstrates the influence of $\mathrm{pH}$ on the stability of W/O/W emulsion stabilized with rice husk silica/Tween20 on the outer emulsion (Sapei et al., 2018). The acidic environment of the outer aqueous phase $(\mathrm{pH}<4)$ enhanced the stabilizing action of rice husk silica particles on the interfacial layer. The silica particles formed a closely congested layer due to the biosilica particle aggregations, thereby improving the barrier properties against droplet coalescences. The resulting double emulsions had in turn higher stabilities of about $97 \%$ after a storage period of 7 days.

Pichot et al. $(2009,2010)$ investigated the effect of surfactant addition on the "food-grade" O/W emulsion stabilized by colloidal hydrophilic silica particles (Aerosil 200). Pichot et al. (2009) found out that the concentration of both monoolein and silica particles influenced the stability of $\mathrm{O} / \mathrm{W}$ emulsion. Initially, monoolein decelerated the coalescence phenomena and further induced droplet break-up, during emulsification, while reducing interfacial tension by rapidly covering the newly created interfaces, thus allowing the deposition of the silica particles at the interfaces to render longterm stability. Pichot et al. (2010) investigated the effect of different emulsifiers' types and concentrations on the $\mathrm{O} / \mathrm{W}$ stability stabilized by colloidal particles. Colloidal silica particles were combined with lecithin and Tween-60/Sodium Caseinate. Emulsion stabilized by mixed emulsifiers and silica particles contained smaller droplets in comparison with the emulsion stabilized by either emulsifiers or silica particles. As the emulsifier concentration increased, dispersed droplets began to increase, followed by the detachment of silica particles from the surfaces. Pichot et al. (2012) investigated the effect of surfactants' concentrations and types (Tween-60, Na-caseinate, and lecithin) on the contact angles and interfacial tensions in the presence of hydrophilic silica particles. The contact angle profile was governed by both emulsifiers and particles at low emulsifier concentration regardless of the surfactant's type, whereas it was influenced by the emulsifier only at high concentration.

Eskandar et al. (2011) investigated the interfacial structure along with the formation and stability of MCT (medium chain triglyceride) or paraffin-based O/W emulsions which were stabilized with either lecithin or oleylamine and nanoparticles of hydrophilic silica (Aerosil 380). A synergism between emulsifiers and hydrophilic silica nanoparticles in stabilizing O/W emulsion was observed. Dyab (2012) investigated the destabilization of Pickering emulsions in the presence of hydrophobic silica fumed nanoparticles by dictating the $\mathrm{pH}$. The results suggested that $\mathrm{pH}$ strongly affected the silica particles' wettability, hence their contact angles. Frelichowska et al. (2010) investigated the stability of O/W emulsions stabilized by hydrophobic fumed silica. Silica particle aggregation became an important parameter for the emulsion stability. A supplementary mechanism of oil adsorption and capillary condensation of oil within the silica aggregates contributed to the stability of emulsion as well. Binks and Whitby (2005) studied the use of hydrophilic nanoparticle silica in stabilizing O/W emulsion. The oil 
used included toluene, heptanes, isopropyl myristate, and methyl myristate. Changes in $\mathrm{pH}$ and the addition of divalent electrolyte altered the particle charge and flocculation causing temporary enhancements in emulsion stability. In addition, the incorporation of cationic type surfactant improved the emulsion stability. The particle layer formed around the droplets sterically hindered the flocculation, thus stabilizing the droplets against coalescences (Binks \& Whitby, 2005). Midmore (1998) observed the synergism action between silica (Ludox) and polyoxyethylene emulsifier during the formation of O/W emulsions. There were three main roles of the surfactant, i.e., promoting solid particle flocculation, modifying the particle wettability, and lowering the interfacial tension. Surfactants played a significant role in modifying the silica surface properties (Lebdioua et al., 2018). Tambe and Sharma (1993) investigated several solid particles including hydrophilic silica in a non-food-grade $\mathrm{O} / \mathrm{W}$ emulsion with n-decane as oil phase. It turned out that low $\mathrm{pH}$ values (4 and 6) favored the formation of highly stable $\mathrm{O} / \mathrm{W}$ emulsions stabilized by silica particles and an emulsifier, vice versa a high $\mathrm{pH}$ value ( 8 and 10$)$ was suitable for achieving W/O emulsion with high stability. W/O emulsions are favored as Dai et al. (2019) observed the formation of solid-like films due to the self-assembly of nanosilica/surfactant at the oilwater interface. Under weakly acidic conditions, higher surface coverage and lower interfacial tension was observed. Ríos et al. (2018) found that silica particles increased the surface activity of anionic surfactant by considerably reducing their critical micelle concentration, while the effects were reversed in case of nonionic surfactants. Silica particles were considered as nontoxic and even reduced the toxicity of surfactant solutions. Pickering emulsion stabilized with silica nanoparticles demonstrated an increase in thermal resistance at high temperatures and remained stable in harsh conditions, thanks to a rigid nanoparticle layer at the oil-water interface (Taherpour \& Hashemi, 2018).

\section{Effect of emulsifier addition combined with rice husk silica in stabilizing $0 / \mathrm{W}$ emulsion}

Pickering emulsions stabilized with particles exhibited a much higher stability when combined with the amphiphilic emulsifiers. It was shown that emulsions involving oil and water were less stable when only solid particles or only emulsifiers were used (Pichot et al., 2009, 2010; Eskandar et al., 2011; Sapei et al., 2017a, 2017b). There was a synergistic mechanism between solid particle and amphiphilic emulsifier in stabilizing O/W emulsion. The polymeric emulsifier was easily adsorbed onto the oilwater interfaces, which lowered the interfacial tension while facilitating the further adsorption of the particles onto the droplet surface providing the steric barrier against droplet coalescences. The emulsions showed higher stability with greater long-term stability (Pichot et al., 2009; Sapei et al., 2017b) and lower destabilization rate constants (Sapei et al., 2017a, 2017b). The effect of the addition of lecithin and Tween-20 together with rice husk silica on the overall stability of $\mathrm{O} / \mathrm{W}$ emulsions was described in the following Sections 3.1 and 3.2, respectively. No $\mathrm{pH}$ adjustment was made during the experiments. However, the slightly acidic $\mathrm{pH}$ of the outer aqueous phase favored the formation of stable O/W emulsion (Tambe \& Sharma, 1993).

\subsection{Addition of lecithin in the oil phase}

The O/W emulsion was prepared by dispersing soybean oil into the aqueous phase with the fraction of $20 \%$. Emulsification was carried out using a rotor-stator homogenizer. Lecithin was added into the oil 
phase, whereas pure biosilica derived from citric acid-leached rice husk (Sapei et al., 2017b) was dispersed in the aqueous phase. Concentrations of lecithin and silica were varied in order to study their effect on the overall emulsion stability as depicted in Table 18.1. The emulsion stability was measured based on the fraction of emulsion and cream indicated by their corresponding height in the glass vial (Sapei et al., 2017a).

The results showed that the $\mathrm{O} / \mathrm{W}$ emulsion without any emulsifiers had the lowest emulsion stability of below $60 \%$ after 2 days. The use of rice husk silica alone as a stabilizer enhanced the emulsion stability. However, when the concentration of silica particles was too low or too high, its emulsion stabilizing ability decreased. The optimum rice husk silica concentration obtained was $2 \%$ indicated by the higher short-term (after $1 \mathrm{~h}$ ) as well as long-term (after 2 days) stability. A minimum concentration of particles is required to sufficiently form a dense layer of particles around the droplets and to modify the degree of interparticle interaction (Tambe \& Sharma, 1993). The solid silica particles would diffuse and adsorb onto the interfacial layer, thus rendering a steric hindrance to inhibit the coalescence of oil droplets and increasing emulsion stability. When the silica particles increase, they tend to sediment since the interaction among particles at the oil-water interface is not strong. The silica particles tend to have negative charges over their surface, thereby increasing the electrostatic repulsion between the particles and lessening the silica flocculation at some degree which is required to form a rigid film barrier. Stabilization of $\mathrm{O} / \mathrm{W}$ emulsion using bare silica particles resulted in an emulsion with low stability since creaming and coalescence occurred rather quickly (Frelichowska et al., 2009).

The addition of lecithin ranged from $0.1 \%$ to $1.5 \%$ did not significantly improve the emulsion stability. In general, an increase in lecithin concentration slightly improved both short-term and longterm emulsion stability. The optimum emulsifier's mixture was found to be $2 \%$ rice husk silica and $1.5 \%$ lecithin which demonstrated the highest short-term emulsion stability. The influence of W/O surfactant on the stability of $\mathrm{O} / \mathrm{W}$ emulsion was almost negligible according to previous investigation (Pichot et al., 2010).

\begin{tabular}{|c|c|c|}
\hline Emulsifiers & $\begin{array}{l}\text { Emulsion stability } \\
\text { after } 1 \mathrm{~h}(\%)\end{array}$ & $\begin{array}{l}\text { Emulsion stability after } \\
2 \text { days }(\%)\end{array}$ \\
\hline No emulsifiers & 71.15 & 59.97 \\
\hline $1 \% \mathrm{~S}$ & 69.23 & 62.18 \\
\hline $2 \% \mathrm{~S}$ & 73.72 & 64.38 \\
\hline $3 \% \mathrm{~S}$ & 71.15 & 61.54 \\
\hline $2 \% \mathrm{~S}+0.1 \% \mathrm{~L}$ & 71.79 & 64.10 \\
\hline $2 \% \mathrm{~S}+0.6 \% \mathrm{~L}$ & 73.08 & 65.10 \\
\hline $2 \% \mathrm{~S}+1 \% \mathrm{~L}$ & 73.72 & 64.46 \\
\hline $2 \% \mathrm{~S}+1.5 \% \mathrm{~L}$ & 74.36 & 63.82 \\
\hline
\end{tabular}




\subsection{Addition of Tween-20 in the aqueous phase}

The $\mathrm{O} / \mathrm{W}$ emulsion with palm oil fraction of $20 \%$ was dispersed in the aqueous phase containing pure biosilica derived from citric acid-leached rice husk (Sapei et al., 2017b) and Tween-20 using a rotor-stator homogenizer. It was obvious as seen in Table 18.2 that $\mathrm{O} / \mathrm{W}$ emulsion prepared without any emulsifiers had the lowest stability of below 50\%. The addition of bare rice husk silica particles up to $2 \%$ increased the emulsion short-term stability of about $33 \%$. Furthermore, the incorporation of $1 \%$ Tween-20 with $2.5 \%$ silica drastically increased the short-term emulsion stability of about $90 \%$ and $43 \%$ compared to those without emulsifiers and with bare rice husk silica, respectively. The long-term emulsion stability was also increased upon the addition of rice husk silica to about $58 \%$ and further increased to about $73 \%$ with the incorporation of Tween-20.

The emulsion stability decreased with time for the first $1 \mathrm{~h}$. after the emulsion preparation, as the function of various rice husk silica concentration could be seen in Fig. 18.2. Similar trends with emulsions prepared with rice husk silica/lecithin showed that the emulsion stability escalated with the increase of rice husk silica concentration until the optimum concentration was reached and then decreased. A minimum amount of silica particles seemed to be required to cover the oil-water interface, thus providing a rigid barrier against oil droplet coalescences. As silica concentrations were further increased, some particles would be more suspended into the aqueous phase prior to sedimentation due to weak particle interaction in the interface region. The particles on the interfacial layer would probably detach and leach into the aqueous phase due to the van der Waals attraction forces among the suspended silica particles and hydrogen bonding among hydroxyls from both silanols and water. It was obvious that at the optimum rice husk silica concentration of $2 \%$, the emulsion stability exhibited higher value compared to others within the timeframe of 10-60 min. This could be due to a higher interaction between silica particles on the interfacial region that made the formation of rigid film possible.

In Fig. 18.3, the emulsion stability profiles all emulsions stabilized with different emulsifiers and without emulsifiers. It was observed that the emulsion stability increased with the sequences as

\section{Table 18.2 Stability of oil-in-water $(\mathrm{O} / \mathrm{W})$ emulsion stabilized by Rice Husk Silica and} Tween-20.

\begin{tabular}{|l|l|l|} 
Emulsifiers & $\begin{array}{l}\text { Emulsion stability } \\
\text { after } \mathbf{1 ~ h}(\%)\end{array}$ & $\begin{array}{l}\text { Emulsion stability } \\
\text { after 2 days (\%) }\end{array}$ \\
No emulsifiers & 46.67 & 42.22 \\
$1 \% \mathrm{~S}$ & 60.00 & 57.78 \\
$2 \% \mathrm{~S}$ & 62.22 & 57.78 \\
$3 \% \mathrm{~S}$ & 44.44 & 40.00 \\
$2.5 \% \mathrm{~S}+0.1 \% \mathrm{~T}$ & 51.11 & 47.78 \\
$2.5 \% \mathrm{~S}+0.3 \% \mathrm{~T}$ & 82.22 & 71.11 \\
$2.5 \% \mathrm{~S}+0.7 \% \mathrm{~T}$ & 86.67 & 73.33 \\
$2.5 \% \mathrm{~S}+1 \% \mathrm{~T}$ & 88.89 & 71.11 \\
\hline Oil phase of 20\% consisted of palm oil was dispersed in aqueous phase containing rice husk silica/Tween-20. The resulting O/W \\
emulsions were stored at room temperature $\left(\sim 28^{\circ} \mathrm{C}\right)$.
\end{tabular}




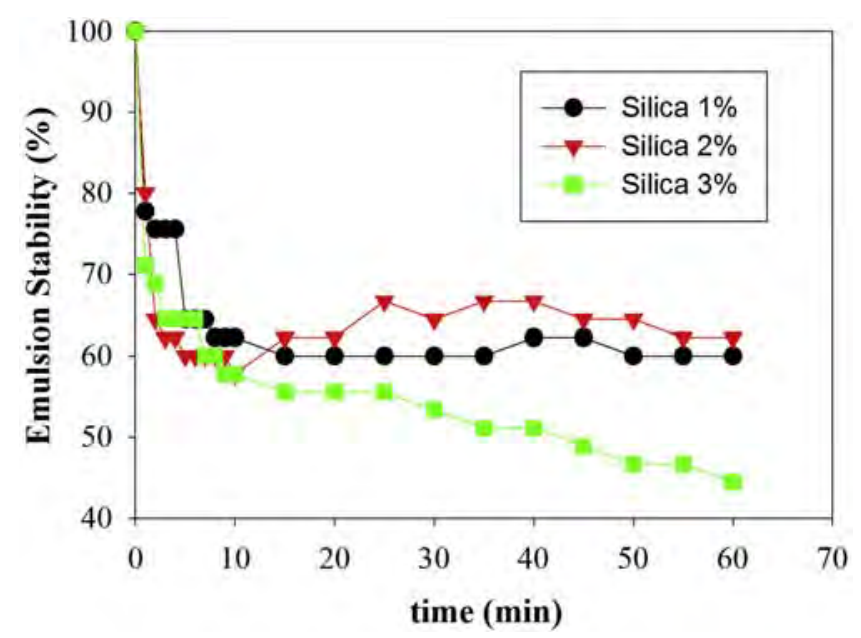

\section{FIGURE 18.2}

Effect of rice husk silica particle concentrations on the oil-in-water $(\mathrm{O} / \mathrm{W})$ emulsion stability. Oil phase of $20 \%$ consisted of palm oil was dispersed in aqueous phase containing rice husk silica. The resulting $\mathrm{O} / \mathrm{W}$ emulsions were stored at room temperature $\left(\sim 28^{\circ} \mathrm{C}\right)$.

follows: mixture of $2.5 \%$ rice husk silica and $1 \%$ Tween-20 $>1 \%$ Tween-20 $>2 \%$ silica $>$ without emulsifier. The results suggested a noticeable enhancement of emulsion stability upon the addition of polymeric surfactant, compared to the use of polymeric surfactant only, or bare silica. This is in line with the earlier tests (Pichot et al., 2009; Sapei et al., 2017b). It seemed plausible that there was a synergism between polymeric surfactant and silica particles in stabilizing the oil-water interfacial region. Besides lowering the interfacial tension, polymeric surfactant could also modify the wettability of rice husk silica particles and induce the flocculation of silica particles, thus facilitating the formation of a rigid barrier against coalescences of oil droplets (Midmore, 1998). The use of polymeric surfactant only seemed to be more effective in increasing the emulsion stability compared to the use of bare rice husk silica. This was due to the higher diffusivity rate of Tween-20 as polymeric surfactant molecules into the interfacial region and their surface activity after being adsorbed onto the interfaces. The use of

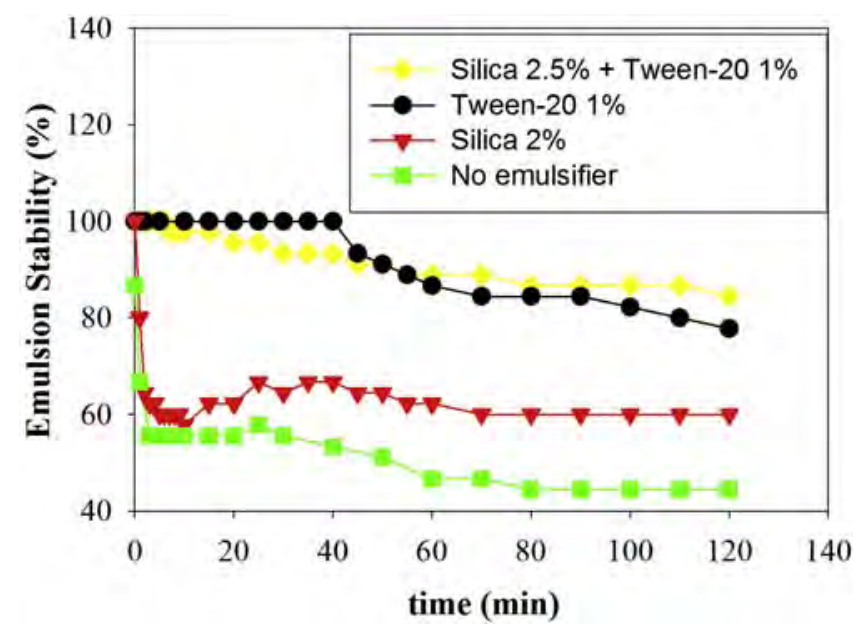

\section{FIGURE 18.3}

Effect of various concentrations of rice husk silica/Tween-20 concentrations on the oil-inwater $(\mathrm{O} / \mathrm{W})$ emulsion stability. Oil phase of $20 \%$ consisted of palm oil was dispersed in aqueous phase containing rice husk silica/ Tween-20. The resulting O/W emulsions were stored at room temperature $\left(\sim 28^{\circ} \mathrm{C}\right)$. 
bare silica particles to improve the emulsion stability has become less effective without the addition of other polymeric surfactant. The use of emulsifier mixtures of rice husk silica/Tween-20 slightly increases the overall emulsion stability compared to that stabilized with Tween-20 only. This might indicate the importance of $\mathrm{O} / \mathrm{W}$ type polymeric surfactant as the predominant factor in enhancing the overall stability of $\mathrm{O} / \mathrm{W}$ emulsion.

\section{Effect of $\mathrm{pH}$ of outer continuous phase on the stability of $\mathrm{O} / \mathrm{W}$ emulsion stabilized with rice husk silica}

The stability of $\mathrm{O} / \mathrm{W}$ emulsion stabilized by silica was influenced by the $\mathrm{pH}$ of the outer aqueous phase. The O/W emulsion using $20 \%$ palm oil and stabilized using $1.5 \%$ rice husk silica combined with Tween-20 1\% was dispersed in the outer aqueous phase with varying $\mathrm{pH}$ of 4.6 (no pH adjustment), 2 , 7, and 10. It could be seen from Fig. 18.4 that the emulsion stability reached its maximum of $100 \%$ at pH 2 and 4.6 after being stored for $60 \mathrm{~min}$ at room temperature. The stability was reduced by approximately $40 \%$ at the higher $\mathrm{pH}$ (7 and 10) of outer aqueous phase. However, the effect of $\mathrm{pH}$ was insignificant for the long-term emulsion stability. The emulsion stabilized with silica gained stability against coalescence when its $\mathrm{pH}$ became acidic. (Tambe \& Sharma, 1993) The emulsifying properties of silica were mostly affected by $\mathrm{pH}$, whereby acidic $\mathrm{pH}$ of less than 4 was preferable to achieve longterm emulsion stability (Pichot et al., 2010). When $\mathrm{pH}$ was below 4, silica particles tended to have no charge (Pichot et al., 2010), although the isoelectric point of the silica particle was around $\mathrm{pH} 2$ (Dyab, 2012). Therefore, the silica particles likely to form closely packed aggregates surrounding the interfacial oil and water surface are more resistant to coalescence (Pichot et al., 2009). On the other hand, at higher $\mathrm{pH}$ (7 and 10), silica would undergo dissociation into $\mathrm{SiO}_{4}{ }^{-}$with the mechanism as follows (Dyab, 2012):

$$
\mathrm{SiOH} \leftrightarrow \mathrm{SiO}^{-}+\mathrm{H}^{+}
$$

\section{FIGURE 18.4}

Effect of $\mathrm{pH}$ of the outer aqueous phase on the stability of oil-in-water emulsion stabilized using $1.5 \%$ silica and $1 \%$ Tween-20 after 60 and $120 \mathrm{~min}$ storage at room temperature $\left(\sim 28^{\circ} \mathrm{C}\right)$. Oil phase of $20 \%$ consisted of palm oil was dispersed in aqueous phase containing rice husk silica/Tween-20.

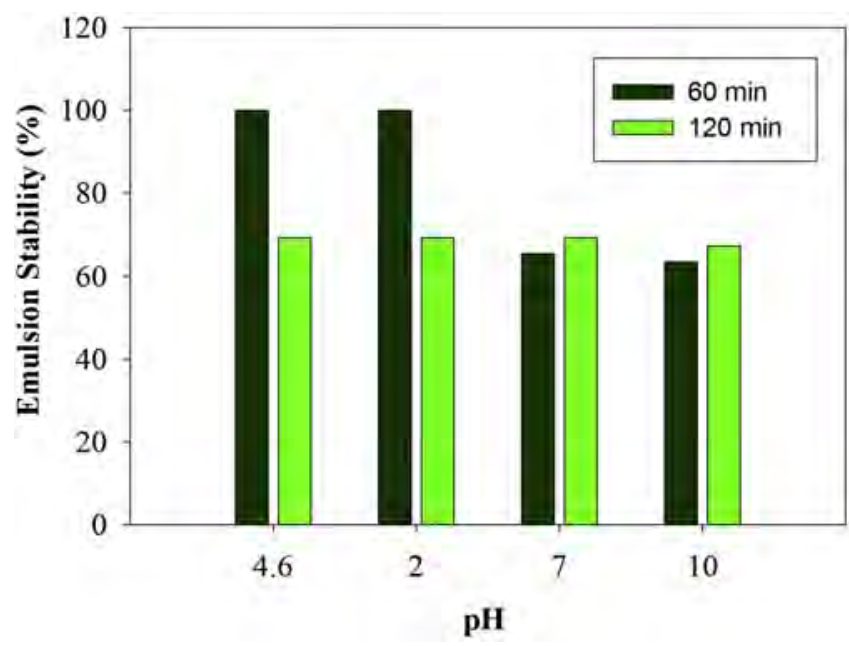




\section{Effect of storage temperature on the stability of O/W emulsion stabilized with

The negatively charged silica particles tended to be hydrophilic. (Dyab, 2012) As silica particles were becoming more hydrophilic, they tended to diffuse into the outer aqueous phase and were less likely to remain within the oil-water interfaces. The negative silica charges favored the electrostatic repulsion among the particles, which hindered the formation of the closely packed layer of silica particles on the interfacial layer. The emulsion stability was therefore decreased as a result of the oil globule coalescences or flocculations due to the weak barrier properties of silica particles on the interfaces. Vice versa, low $\mathrm{pH}$ would result in more hydrophobic and chargeless silica particles. If particles were either very hydrophilic $\left(\theta<<90^{\circ}\right)$ or very hydrophobic $\left(\theta>>90^{\circ}\right)$, they were easily removed from the interface (Binks \& Rodrigues, 2009). Low $\mathrm{pH}$ of outer continuous phase proved to produce higher stability of $\mathrm{W} / \mathrm{O} / \mathrm{W}$ emulsion stabilized by rice husk silica according to our previous investigation (Sapei et al., 2018). The proposed mechanisms of rice husk silica stabilization upon basic and alkaline $\mathrm{pH}$ has also been described (Sapei et al., 2018). The $\mathrm{pH}$ of the system seemed to play a significant part in influencing the wettability of silica particles and in establishing a stable $\mathrm{O} / \mathrm{W}$ emulsion.

\section{Effect of storage temperature on the stability of $0 / W$ emulsion stabilized with rice husk silica}

The emulsion stability was highly dependent on temperature. The effect of storage temperatures on the stability of $\mathrm{O} / \mathrm{W}$ emulsion stabilized by rice husk silica/lecithin and rice husk silica/Tween-20 could be seen in Figs. 18.5 and 18.6, respectively. It was obvious that the stability of emulsion stored at the refrigerated temperature $\left(\sim 8^{\circ} \mathrm{C}\right)$ was higher than that of emulsion stored at the room temperature $\left(\sim 28^{\circ} \mathrm{C}\right)$. The increased stability at $8^{\circ} \mathrm{C}$ was obviously seen after $40 \mathrm{~min}$ in the emulsion stabilized using silica/Tween 20. Furthermore, in all $\mathrm{O} / \mathrm{W}$ emulsions stabilized with silica and varying amount of lecithin showed a slight increase in the overall stability when emulsions were stored at $8^{\circ} \mathrm{C}$. The gradual and slight increase in emulsion stability was due to the gradual cooling of the emulsions upon storage in the refrigerator. In general, the emulsion was becoming more stable at the lower temperature. As temperatures lowered, the viscosity of the emulsion increased, thus decreasing the rate of creaming according to Eq. (18.1) (McClements, 2007). The decrease in creaming velocity was due to the slowing down of oil globule flocculations or coalescences at decreasing temperatures.

$$
v_{\text {Stokes }}=\frac{2 g r^{2}\left(\rho_{2}-\rho_{1}\right)}{9 \eta_{1}}
$$

where $v_{\text {Stokes }}$ is creaming velocity, $g$ is gravitational acceleration, $r$ is droplet radius, $\rho$ is density, $\eta$ is viscosity, and subscripts of 1 and 2 are denoted to continuous phase and dispersed phase, respectively.

The increased stability of $\mathrm{O} / \mathrm{W}$ emulsions stored at low temperatures could be observed microscopically as seen in Figs. 18.7 and 18.8. It was observed that both O/W emulsion stabilization using $2 \%$ silica $1.5 \%$ lecithin and $2.5 \%$ silica/ $1 \%$ Tween- 20 demonstrated smaller oil droplets dispersed in the aqueous phase at refrigerated temperatures (Fig. 18.7B vs. 18.7C and Fig. 18.8B vs. 18.8C). The smaller the oil globules, the more stable the emulsion. This again inferred the increasing stability of $\mathrm{O} / \mathrm{W}$ emulsions upon storage at low temperatures. The rate of coalescence and creaming was decreased as emulsion viscosity tended to be increased with the lower temperature. 


\section{FIGURE 18.5}

Effect of storage temperature on the stability of oil-in-water emulsion stabilized using $2 \%$ silica combined with various concentration of lecithin after $60 \mathrm{~min}$ and 2 day storage. Oil phase of $20 \%$ consisted of soybean oil and lecithin was dispersed in aqueous phase containing rice husk silica.

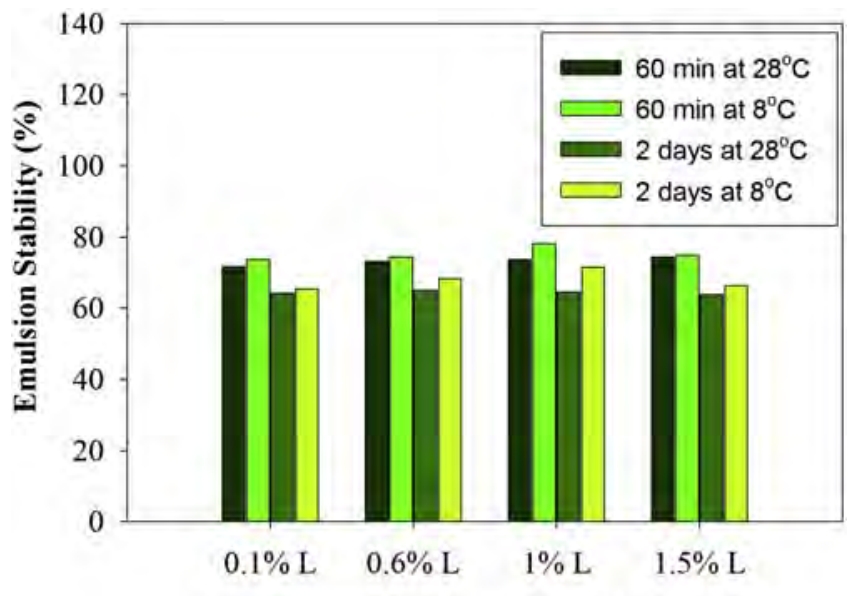

Lecithin concentration (\%)

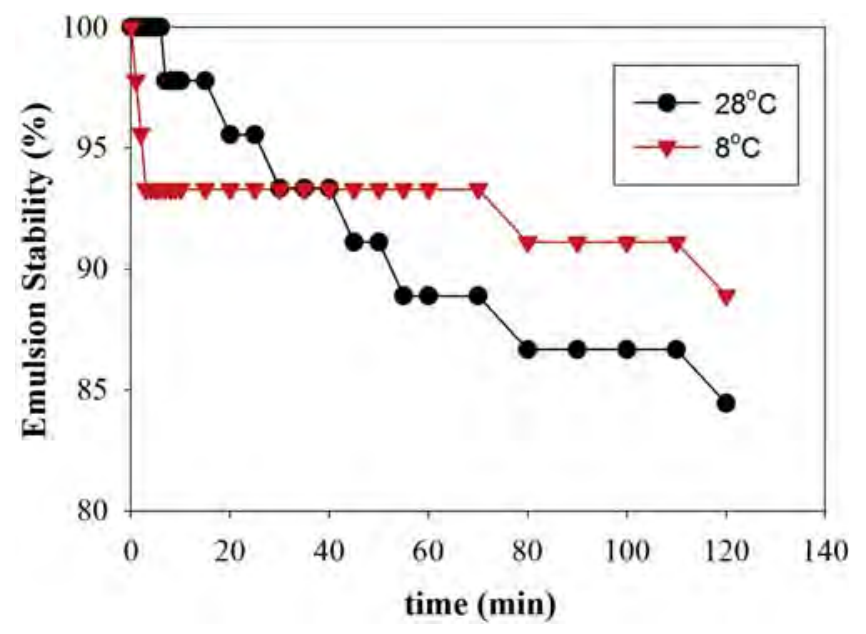

\section{Kinetics study on the stability of $0 / \mathrm{W}$ emulsion stabilized with rice husk silica}

Research has shown that a O/W emulsion tended toward instability with time, since it was an inherently thermodynamically unstable system. However, the emulsion could be presumed to be stable when it demonstrated a high kinetic stability. The kinetic stability of the emulsion was able to be increased by many means including the choice of emulsifiers, ratio of all components added into the formulation, presence of additives, emulsification techniques, and condition during emulsification. The instability of emulsions was caused by several phenomena such as flocculation, coalescences, 

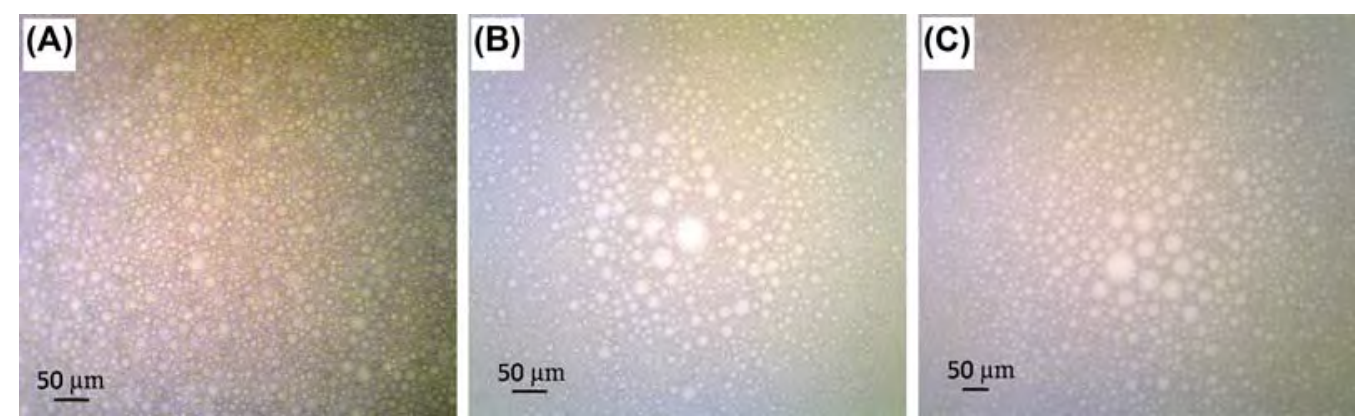

\section{FIGURE 18.7}

The microscopic images of oil-in-water emulsions stabilized with $2 \%$ rice husk silica and $1.5 \%$ lecithin. Oil phase of $20 \%$ consisted of soybean oil and lecithin was dispersed in aqueous phase containing rice husk silica. (A) After emulsification, (B) after $3 \mathrm{~h}$ storage at room temperature $\left(\sim 28^{\circ} \mathrm{C}\right)$, and $(\mathrm{C})$ after $3 \mathrm{~h}$ storage at refrigerated temperature $\left(\sim 8^{\circ} \mathrm{C}\right)$.

Ostwald ripening, creaming, sedimentation, phase inversion, and phase separation (McClements, 2007).

In $\mathrm{O} / \mathrm{W}$ emulsions systems, creaming generally occurred as the result of oil globule flocculation followed by coalescences. The oil globules became larger upon coalescences, thereby increasing the creaming rate leading to emulsion instability. The kinetics of emulsion destabilization was studied in some of our experiments in order to determine the effect of different emulsifier mixtures involving the use of rice husk silica upon the Pickering emulsion stabilization. It has been known that the coalescence rate of the dispersed phase globules followed the first kinetic model (Wanli et al., 2000).

The data within the first 20-40 min and between 0 and 120 min were selected for the determination of the destabilization kinetics of $\mathrm{O} / \mathrm{W}$ emulsion stabilized by rice husk silica/lecithin and rice
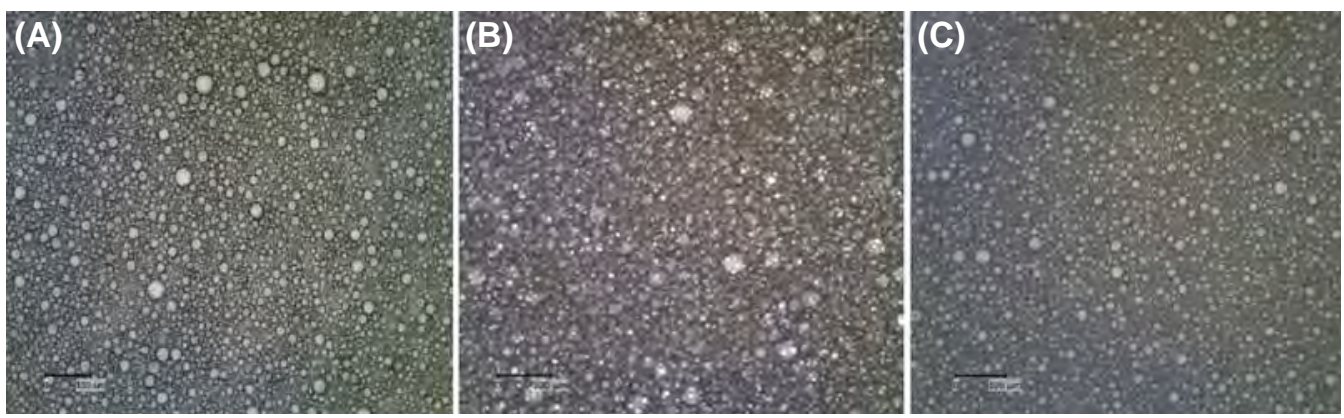

\section{FIGURE 18.8}

The microscopic images of oil-in-water emulsions stabilized with $2.5 \%$ rice husk silica and $1 \%$ Tween-20. Oil phase of $20 \%$ consisted of palm oil was dispersed in aqueous phase containing rice husk silica and Tween20. (A) After emulsification, (B) after $2 \mathrm{~h}$ storage at room temperature $\left(\sim 28^{\circ} \mathrm{C}\right)$, and $(\mathrm{C})$ after $2 \mathrm{~h}$ storage at refrigerated temperature $\left(\sim 8^{\circ} \mathrm{C}\right)$. 


\section{Chapter 18 Rice husk silica for the stabilization}

husk silica/Tween-20, respectively. The emulsion stability data remained quite constant after those specified timeframe. The stability data of $\mathrm{O} / \mathrm{W}$ emulsion were evaluated in time using the zero-order or first-order kinetic models to determine the constant destabilization rate. The least square procedure was applied in order to determine the most appropriate kinetic order based on the best obtained correlation coefficient $\left(\mathrm{R}^{2}\right)$. The emulsion destabilization rate was represented by Eq. (18.2), while the zero-order and first-order kinetics models were represented by Eqs. (18.3) and (18.4), respectively (Levenspiel, 1999):

$$
\begin{aligned}
-r & =-\frac{d Z}{d t}=k Z^{a} \\
Z & =Z_{0}-k_{0} t \\
\ln (Z) & =\ln \left(Z_{0}\right)-k_{1} t
\end{aligned}
$$

where $-\frac{d Z}{d t}$ the emulsion destabilization rate, a the emulsion destabilization rate order, $k_{0}$ and $k_{1}$ the destabilization rate constants of emulsions for the zero order (\% stability/minute) and first order (per minute), respectively, $t$ the storage time (minute), $Z$ the emulsion stability percentage after time $t$, and $Z_{0}$ the initial emulsion stability percentage.

The kinetics data of $\mathrm{O} / \mathrm{W}$ emulsion stabilized by rice husk silica/lecithin and rice husk silica/ Tween-20 were depicted in Tables 18.3 and 18.4 respectively. Soybean oil was used for the emulsions stabilized with silica/lecithin, whereas palm oil was used for the emulsions stabilized with silica/Tween-20. Generally, the destabilization process of all O/W emulsions was fitted more closely to the first-order kinetic models compared to the zero-order kinetic models. This was reflected by the higher $\mathrm{R}^{2}$ obtained from the fitting of the experimental data with the first-order kinetic model. Silica of different concentrations ranged from $1 \%$ to $3 \%$ was investigated in a soybean/water system. The lowest destabilization rate $(\mathrm{k})$ of $1.3 \times 10^{-3} \mathrm{~min}^{-1}$ was found in the $\mathrm{O} / \mathrm{W}$ emulsion stabilized with $2 \%$ silica as could be seen in Table 18.3. When the concentration of silica was decreased into $1 \%$ or increased into $3 \%$, the $\mathrm{k}$ values were lowered by around 3 and 7 times, respectively. This implied that there was an optimum concentration of rice husk silica that was needed to help stabilize the $\mathrm{O} / \mathrm{W}$ emulsion. When the silica particle concentration was too low, there would not be sufficient coverage of silica on the interfacial layer. In contrast, when the silica particle concentration was too high, silica particles tended to be leached out to the outer aqueous phase due to the hydrophilicity of biosilica particles. The huge decrease in emulsion stability occurred with time since the particle silica on the interfacial layer was probably detached from the interface due to the hydrogen bonding interaction between the hydroxyl groups of silanol present in biosilica and water. As particle density at the oil-water interface decreased, the emulsion stability also decreased (Wang et al., 2010).

Furthermore, there was an increase in $\mathrm{O} / \mathrm{W}$ emulsion stability as concentrations of lecithin were increased, combined with the consistent concentration of rice husk silica. This was reflected by the decreased $\mathrm{k}$ with the increased lecithin concentration. This may indicate the role of lecithin in assisting the deposition of silica particles onto the interfacial layer, thus improving the barrier properties of the emulsifier layer against flocculations or coalescences. However, the synergistic action between silica and lecithin was not obvious, since the addition of lecithin did not decrease the $\mathrm{k}$ value by much and was comparable with that obtained when no emulsifier at all was used with $\mathrm{k}$ of $2.5 \times 10^{-3} \mathrm{~min}^{-1}$ (Sapei et al., 2017a). The lowest $\mathrm{k}$ was achieved by the use of $2 \%$ silica only and 
Table 18.3 Kinetic oil-in-water emulsion-destabilizing rate constants and $R^{2}$ values according to zero-order and first-order kinetic models for emulsions stabilized with rice husk silica/ lecithin.

\begin{tabular}{|c|c|c|c|c|c|}
\hline \multirow[b]{2}{*}{ Emulsifiers } & \multirow{2}{*}{$\begin{array}{l}\begin{array}{l}\text { Storage } \\
\text { temperature }\end{array} \\
\mathbf{T}\left({ }^{\circ} \mathrm{C}\right)\end{array}$} & \multicolumn{2}{|l|}{ Order 0} & \multicolumn{2}{|c|}{ Order 1} \\
\hline & & $\mathbf{k}_{0}(\%$ stability/min $)$ & $\mathbf{R}^{2}$ & $k_{1} \times 10^{3}\left(\min ^{-1}\right)$ & $\mathbf{R}^{2}$ \\
\hline S $1 \%$ & 28 & 0.3669 & 0.9541 & 3.9 & 0.9586 \\
\hline S $2 \%$ & 28 & 0.1293 & 0.8044 & 1.3 & 0.8071 \\
\hline S 3\% & 28 & 0.8107 & 0.9082 & 9.6 & 0.9064 \\
\hline $\begin{array}{l}\text { S } 2 \%+\mathrm{L} \\
0.1 \%\end{array}$ & 28 & 0.382 & 0.9651 & 4.0 & 0.9688 \\
\hline $\mathrm{S} 2 \%+\mathrm{L} 1 \%$ & 28 & 0.3573 & 0.8048 & 3.7 & 0.8103 \\
\hline $\begin{array}{l}\text { S } 2 \%+\mathrm{L} \\
1.5 \%\end{array}$ & 28 & 0.2185 & 0.8723 & 2.3 & 0.8789 \\
\hline $\begin{array}{l}\text { S } 2 \%+\mathrm{L} \\
0.1 \%\end{array}$ & 8 & 0.315 & 0.9844 & 3.3 & 0.9863 \\
\hline $\mathrm{S} 2 \%+\mathrm{L} 1 \%$ & 8 & 0.1523 & 0.8055 & 1.6 & 0.8118 \\
\hline $\begin{array}{l}\mathrm{S} 2 \%+\mathrm{L} \\
1.5 \%\end{array}$ & 8 & 0.1869 & 0.8954 & 1.9 & 0.9001 \\
\hline
\end{tabular}

Oil phase of $20 \%$ consisted of soybean oil/lecithin was dispersed in aqueous phase containing rice husk silica.

$S$ and $L$ denoted as silica and lecithin, respectively.

Table 18.4 Kinetic oil-in-water $(\mathrm{O} / \mathrm{W})$ emulsion-destabilizing rate constants and $\mathrm{R}^{2}$ values according to zero-order and first-order kinetic models for emulsions stabilized with rice husk silica/Tween-20.

\begin{tabular}{|l|l|l|l|l|} 
& \multicolumn{2}{|c|}{ Order 0 } & \multicolumn{2}{c|}{ Order 1 } \\
\cline { 2 - 4 } Emulsifiers & $\mathbf{k}_{\mathbf{0}}$ (\% stability/min) & $\mathbf{R}^{\mathbf{2}}$ & $\mathbf{k}_{\mathbf{1}} \times \mathbf{1 0}^{\mathbf{3}}\left(\mathbf{m i n}^{-\mathbf{1}}\right)$ & $\mathbf{R}^{\mathbf{2}}$ \\
Without emulsifiers & 4.9621 & 0.9235 & 72.5 & 0.9434 \\
$\mathrm{~S} 2.5 \%$ & 5.7525 & 0.7749 & 72.4 & 0.7937 \\
$1 \% \mathrm{~T}$ & 0.3524 & 0.9460 & 4.0 & 0.9540 \\
$2.5 \% \mathrm{~S}+0.1 \% \mathrm{~T}$ & 1.7681 & 0.9119 & 23.1 & 0.9321 \\
$2.5 \% \mathrm{~S}+0.3 \% \mathrm{~T}$ & 0.2326 & 0.9634 & 2.7 & 0.9769 \\
$2.5 \% \mathrm{~S}+0.7 \% \mathrm{~T}$ & 0.1824 & 0.9447 & 2.0 & 0.9568 \\
$2.5 \% \mathrm{~S}+1 \% \mathrm{~T}$ & 0.1390 & 0.9349 & 1.5 & 0.9422 \\
\hline
\end{tabular}

Oil phase of $20 \%$ consisted of palm oil was dispersed in aqueous phase containing rice husk silica/Tween-20. The resulting O/W emulsions were stored at room temperature $\left(\sim 28^{\circ} \mathrm{C}\right)$.

$S$ and $T$ denoted as silica and Tween-20, respectively. 
was comparable with the use of $2 \%$ silica $/ 1 \%$ lecithin upon storage at $8^{\circ} \mathrm{C}$. This implied that the addition of lecithin did not significantly influence the overall $\mathrm{O} / \mathrm{W}$ emulsion. This was also corroborated by the previous investigation that the concentration of W/O surfactant within the emulsifier mixture did not significantly affect the stability of $\mathrm{O} / \mathrm{W}$ emulsion system (Pichot et al., 2010). The silica particle seemed to predominantly determine the emulsion stability. However, the effectiveness of the silica particle as an emulsifier was influenced by $\mathrm{pH}$ which modulated its wettability on the interfacial layer. The emulsion stability could have been maximized by changing the $\mathrm{pH}$ into acidic which helps increase the performance of the silica particle on the interfaces as having been described in the previous section. The rate of emulsion destabilization was up to 2.3 times lower when the emulsion was stored at the refrigerated temperature. This confirmed that low storage temperature increases the emulsion stability.

When rice husk silica was mingled with various Tween-20 as the $\mathrm{O} / \mathrm{W}$ surfactant, it was obvious that the constant destabilization rate decreased as the concentration of Tween-20 increased, as seen in Table 18.4. This demonstrated the synergistic action between rice husk silica and Tween-20 in stabilizing the $\mathrm{O} / \mathrm{W}$ emulsion. The Tween-20 surfactant would easily adhere to the oil-water interface and facilitate the attachment of rice husk silica on the interface. Therefore, a rigid layer of silica on the interface would prevent the oil globule coalescences. The lowest $\mathrm{k}$ of $1.5 \times 10^{-3} \mathrm{~min}^{-1}$ was attained with the use of $2.5 \%$ rice husk silica/ $1 \%$ Tween- 20 as mixed emulsifiers. In contrast to silica/lecithinstabilized O/W emulsion whereby lecithin showed no effect on the emulsion stability, Tween-20 seemed to play a significant role in achieving an emulsion with high stability. A tremendous decrease in emulsion stability was observed upon the use of silica alone or without emulsifiers at all reflected by the very high $\mathrm{k}$ value of about $72 \times 10^{-3} \mathrm{~min}^{-1}$. Based on these experiments, the presence of Tween-20 was crucial in producing a highly stable $\mathrm{O} / \mathrm{W}$ emulsion stabilized by rice husk silica. The presence of surfactant could modify the wetting properties of the solids and likely enhance the interparticle interactions (Tambe \& Sharma, 1993).

In summary, the stabilizing capability of rice husk silica in an oil-water interface was governed by $\mathrm{pH}$, temperature, and added surfactant. The improved stability of Pickering emulsions with respect to polymeric emulsifiers stabilized classical emulsions especially for food applications would be a great advantage. The development of emulsions without the use of emulsifiers have attracted particular attention since emulsifiers may cause some adverse effects, such as air entrapment, foaming, irritancy, and detrimental interaction with living matter (Frelichowska et al., 2010). Rice husk silica seems promising to be used as the stabilizing agent of oil droplets while reducing the use of emulsifiers for the formulations of various $\mathrm{O} / \mathrm{W}$ emulsion-based processed food products. Rice husk biosilicastabilizing Pickering emulsions would also demonstrate the great potential as an encapsulation vehicle combined with the controlled release mechanism of bioactive ingredients for developing highly nutritious and healthful food products.

\section{Acknowledgments}

The research was partially funded by Ministry of Research, Technology and Higher Education of the Republic of Indonesia under the research grant scheme of "Fundamental Research" 2019 under the contract number: 004/ SP2H/LT/MULTI/L7/2019. 


\section{References}

Al-Sahhaf, T.A., Fahim, M.A., Elsharkawy, A.M., 2009. Effect of inorganic solids, wax to asphaltene ratio, and water cut on the stability of water-in-crude oil emulsions. Journal of Dispersion Science and Technology 30 (5), 597-604.

Aveyard, R., Binks, B., Clint, J., 2003. Emulsions stabilised solely by colloidal particles. Advances in Colloid and Interface Science 100-102, 503-546.

Binks, B.P., 2002. Particles as surfactants-similarities and differences. Current Opinion in Colloid \& Interface Science 7 (1-2), 21-41.

Binks, B.P., Rodrigues, J.A., 2009. Influence of surfactant structure on the double inversion of emulsions in the presence of nanoparticles. Colloids and Surfaces A: Physicochemical and Engineering Aspects 345 (1-3), 195-201.

Binks, B.P., Whitby, C.P., 2005. Nanoparticle silica-stabilised oil-in-water emulsions: improving emulsion stability. Colloids and Surfaces A: Physicochemical and Engineering Aspects 253 (1-3), 105-115.

Binks, B., Murakami, R., Armes, S., Fujii, S., 2006. Effects of pH and salt concentration on oil-in-water emulsions stabilized solely by nanocomposite microgel particles. Langmuir 22 (5), 2050-2057.

Dai, C., Huang, Y., Lyu, X., Li, L., Sun, Y., Zhao, M., Zhao, G., Wu, Y., 2019. Solid-like film formed by nanosilica self-assembly at oil-water interface. Chemical Engineering Science 195, 51-61.

Dai, L., Sun, C., Wei, Y., Mao, L., Gao, Y., 2018a. Characterization of Pickering emulsion gels stabilized by zein/ gum Arabic complex colloidal nanoparticles. Food Hydrocolloids 74, 239-248.

Dai, L., Zhan, X., Wei, Y., Sun, C., Mao, L., McClements, D.J., Gao, Y., 2018b. Composite zein-propylene glycol alginate particles prepared using solvent evaporation: characterization and application as Pickering emulsion stabilizers. Food Hydrocolloids 85, 281-290.

Dyab, A., 2012. Destabilisation of Pickering emulsions using pH. Colloids and Surfaces A: Physicochemical and Engineering Aspects 402, 2-12.

Eskandar, N., Simovic, S., Prestidge, C., 2011. Interactions of hydrophilic silica nanoparticles and classical surfactants at non-polar oil-water interface. Journal of Colloid and Interface Science 358 (1), $217-225$.

Frelichowska, J., Bolzinger, M., Chevalier, Y., 2009. Pickering emulsions with bare silica. Colloids and Surfaces A: Physicochemical and Engineering Aspects 343 (1-3), 70-74.

Frelichowska, J., Bolzinger, M., Chevalier, Y., 2010. Effects of solid particle content on properties of o/w Pickering emulsions. Journal of Colloid and Interface Science 351 (2), 348-356.

Hong, J.S., Fischer, P., 2016. Bulk and interfacial rheology of emulsions stabilized with clay particles. Colloids and Surfaces A: Physicochemical and Engineering Aspects 508, 316-326.

Koglin, A., Doetsch, V., Bernhard, F., 2010. Molecular engineering aspects for the production of new and modified biosurfactants. In: Sen, R. (Ed.), Biosurfactants. Advances in Experimental Medicine and Biology, vol. 672. Springer, New York, pp. 158-169.

Lebdioua, K., Aimable, A., Cerbelaud, M., Videcoq, A., Peyratout, C., 2018. Influence of different surfactants on Pickering emulsions stabilized by submicronic silica particles. Journal of Colloid and Interface Science 520, 127-133.

Levenspiel, O., 1999. Chemical Reaction Engineering, third ed. John Wiley \& Sons, Inc, New York, pp. 47-51.

Li, X.M., Xie, Q.T., Zhu, J., Pan, Y., Meng, R., Zhang, B., Chen, H.Q., Jin, Z.Y., 2019. Chitosan hydrochloride/ carboxymethyl starch complex nanogels as novel Pickering stabilizers: physical stability and rheological properties. Food Hydrocolloids 93, 215-225.

Lu, X., Xiao, J., Huang, Q., 2018. Pickering emulsions stabilized by media-milled starch particles. Food Research International 105, 140-149. 
Martin, K.R., 2007. The chemistry of silica and its potential health benefits. The Journal of Nutrition, Health \& Aging 11 (2), 94.

McClements, D., 2007. Critical review of techniques and methodologies for characterization of emulsion stability. Critical Reviews in Food Science and Nutrition 47 (7), 611-649.

Midmore, B., 1998. Synergy between silica and polyoxyethylene surfactants in the formation of O/W emulsions. Colloids and Surfaces A: Physicochemical and Engineering Aspects 145, 133-143.

Pichot, R., Spyropoulos, F., Norton, I., 2009. Mixed-emulsifier stabilised emulsions: investigation of the effect of monoolein and hydrophilic silica particle mixtures on the stability against coalescence. Journal of Colloid and Interface Science 329 (2), 284-291.

Pichot, R., Spyropoulos, F., Norton, I., 2010. O/W emulsions stabilised by both low molecular weight surfactants and colloidal particles: the effect of surfactant type and concentration. Journal of Colloid and Interface Science 352 (1), 128-135.

Pichot, R., Spyropoulos, F., Norton, I., 2012. Competitive adsorption of surfactants and hydrophilic silica particles at the oil-water interface: interfacial tension and contact angle studies. Journal of Colloid and Interface Science 377 (1), 396-405.

Pickering, S.U., 1907. Cxcvi.-emulsions. Journal of the Chemical Society Transactions 91, 2001-2021.

Ramsden, W., 1903. The separation of solid materials on the surface of solutions and suspensions. Observations concerning surface diaphragms, foam blisters, emulsions and mechanical coagulation. Proceedings of the Royal Society 72, 156-164.

Reger, M., Sekine, T., Hoffmann, H., 2012. Pickering emulsions stabilized by amphiphile covered clays. Colloids and Surfaces A: Physicochemical and Engineering Aspects 413, 25-32.

Reger, M., Sekine, T., Okamoto, T., Watanabe, K., Hoffmann, H., 2011. Pickering emulsions stabilized by novel clay-hydrophobin synergism. Soft Matter 7 (22), 11021-11030.

Ríos, F., Fernández-Arteaga, A., Fernández-Serrano, M., Jurado, E., Lechuga, M., 2018. Silica micro-and nanoparticles reduce the toxicity of surfactant solutions. Journal of Hazardous Materials 353, 436-443.

Sapei, L., Adiarto, T., Handomo, R., Chandra, S.H., 2018. Effect of $\mathrm{pH}$ on the stability of W1/O/W2 double emulsion stabilized by combination of biosilica and Tween-20. In: Matec Web of Conferences: The 2nd International Conferences on Technology, Innovation, Society and Science-to-Business (ICTIS 2018), vol. 215. EDP Sciences.

Sapei, L., Damayanti, O., Liliana, L., 2017a. Kinetics of oil-in-water emulsion stabilization using lecithin and biosilica. ASEAN Journal of Chemical Engineering 17 (1), 8-21.

Sapei, L., Gierlinger, N., Hartmann, J., Nöske, R., Strauch, P., Paris, O., 2007. Structural and analytical studies of silica accumulations in Equisetum hyemale. Analytical and Bioanalytical Chemistry 389 (4), 1249-1257.

Sapei, L., Nöske, R., Strauch, P., Paris, O., 2008. Isolation of mesoporous biogenic silica from the perennial plant Equisetum hyemale. Chemistry of Materials 20 (5), 2020-2025.

Sapei, L., Sandy, I., Suputra, I., Ray, M., 2017b. The effect of different concentrations of tween-20 combined with rice husk silica on the stability of o/w emulsion: a kinetic study. In: IOP Conference Series: Materials Science and Engineering, vol. 273. Institute of Physics Publishing.

Simmons, A., Schlezinger, J., Corkey, B., 2014. What are we putting in our food that is making us fat? Food additives, contaminants, and other putative contributors to obesity. Current Obesity Reports 3 (2), 273-285.

Taherpour, A., Hashemi, A., 2018. A novel formulation of the pickering emulsion stabilized with silica nanoparticles and its thermal resistance at high temperatures. Journal of Dispersion Science and Technology 39 (12), 1710-1720.

Tambe, D.E., Sharma, M.M., 1995. Factors controlling the stability of colloid-stabilized emulsions: III. Measurement of the rheological properties of colloid-laden interfaces. Journal of Colloid and Interface Science $171(2), 456-462$. 
Tambe, D.E., Sharma, M.M., 1993. Factors controlling the stability of colloid-stabilized emulsions: I. An experimental investigation. Journal of Colloid and Interface Science 157 (1), 244-253.

Tcholakova, S., Denkov, N.D., Lips, A., 2008. Comparison of solid particles, globular proteins and surfactants as emulsifiers. Physical Chemistry Chemical Physics 10 (12), 1608-1627.

Urdahl, O., Sjöblom, J., 1995. Water-in-crude oil emulsions from the Norwegian Continental Shelf. A stabilization and destabilization study. Journal of Dispersion Science and Technology 16 (7), 557-574.

Wang, S., He, Y., Zou, Y., 2010. Study of Pickering emulsions stabilized by mixed particles of silica and calcite. Particuology 8 (4), 390-393.

Wang, W., Zhou, Z., Nandakumar, K., Xu, Z., Masliyah, J.H., 2004. Effect of charged colloidal particles on adsorption of surfactants at oil-water interface. Journal of Colloid and Interface Science 274 (2), 625-630.

Wanli, K., Yi, L., Baoyan, Q., Guangzhi, L., Zhenyu, Y., Jichun, H., 2000. Interactions between alkali/surfactant/ polymer and their effects on emulsion stability. Colloids and Surfaces A: Physicochemical and Engineering Aspects 175 (1-2), 243-247.

Xie, X., Wang, Y., Li, X., Wei, X., Yang, S., 2018. Pickering emulsions stabilized by amphiphilic carbonaceous materials derived from wheat straw. Colloids and Surfaces A: Physicochemical and Engineering Aspects 558, $65-72$.

Yang, Y., Fang, Z., Chen, X., Zhang, W., Xie, Y., Chen, Y., Yuan, W., 2017. An overview of pickering emulsions: solid-particle materials, classification, morphology, and applications. Frontiers in Pharmacology 8, 287. 


\section{BIOPOLYMER-BASED FORMULATIONS}

BIOMEDICAL AND FOOD APPLICATIONS

EDITED BY

KUNAL PAL, INDRANIL BANERJEE, PREETAM SARKAR, DOMAN KIM, WIN-PING DENG, NAVNEET KUMAR DUBEY AND KAUSTAV MAJUMDER
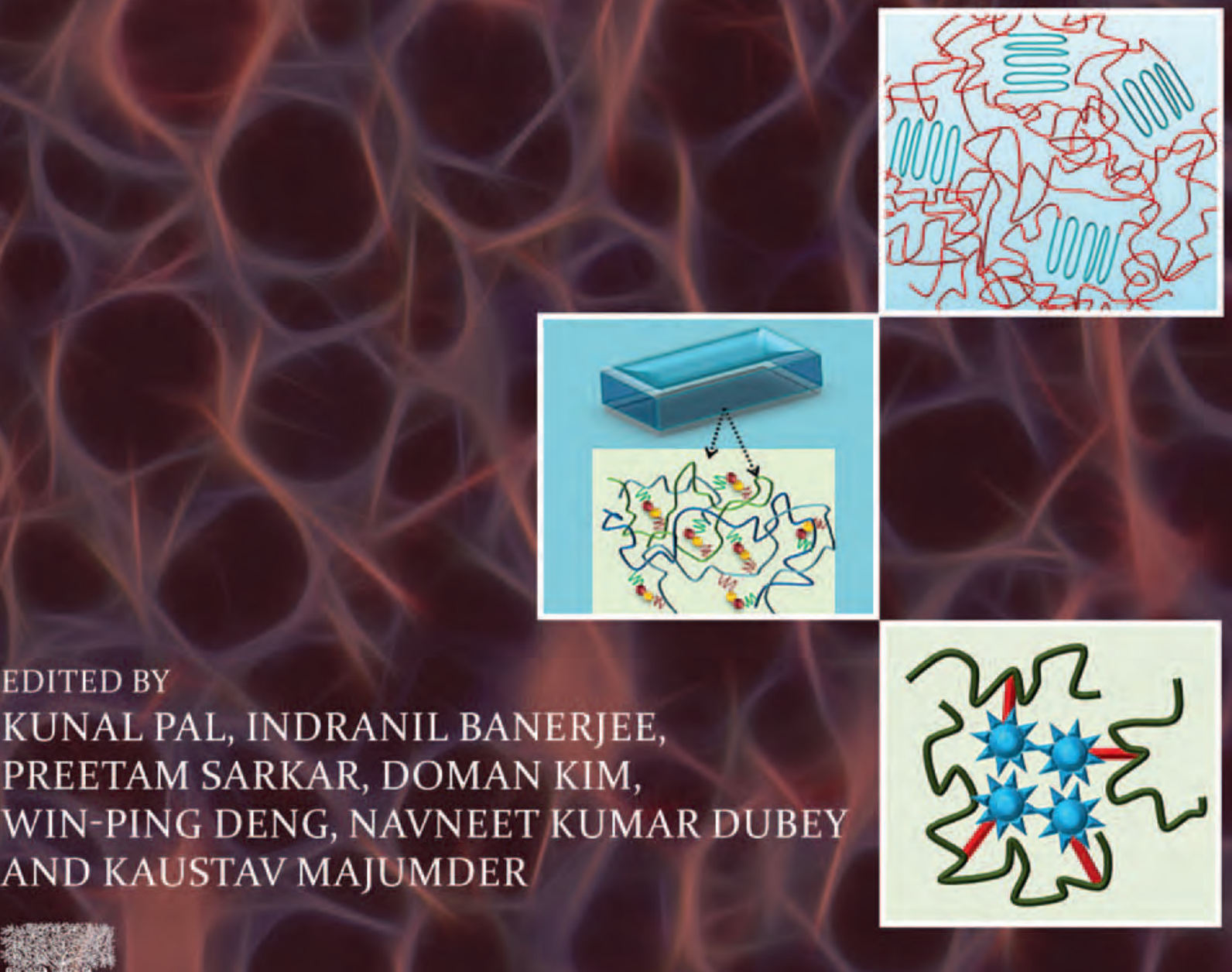


\section{Biopolymer-Based Formulations}


This page intentionally left blank 


\section{Biopolymer-Based Formulations \\ Biomedical and Food Applications}

Edited by

Kunal Pal

Indranil Banerjee

Preetam Sarkar

Doman Kim

Win-Ping Deng

Navneet Kumar Dubey

Kaustav Majumder 
Elsevier

Radarweg 29, PO Box 211, 1000 AE Amsterdam, Netherlands

The Boulevard, Langford Lane, Kidlington, Oxford OX ${ }_{5} 1 \mathrm{~GB}$, United Kingdom

50 Hampshire Street, 5th Floor, Cambridge, MA 02139, United States

Copyright (C) 2020 Elsevier Inc. All rights reserved

No part of this publication may be reproduced or transmitted in any form or by any means, electronic or mechanical, including photocopying, recording, or any information storage and retrieval system, without permission in writing from the publisher. Details on how to seek permission, further information about the Publisher's permissions policies and our arrangements with organizations such as the Copyright Clearance Center and the Copyright Licensing Agency, can be found at our website: www.elsevier.com/permissions.

This book and the individual contributions contained in it are protected under copyright by the Publisher (other than as may be noted herein).

\section{Notices}

Knowledge and best practice in this field are constantly changing. As new research and experience broaden our understanding, changes in research methods, professional practices, or medical treatment may become necessary.

Practitioners and researchers must always rely on their own experience and knowledge in evaluating and using any information, methods, compounds, or experiments described herein. In using such information or methods they should be mindful of their own safety and the safety of others, including parties for whom they have a professional responsibility.

To the fullest extent of the law, neither the Publisher nor the authors, contributors, or editors, assume any liability for any injury and/or damage to persons or property as a matter of products liability, negligence or otherwise, or from any use or operation of any methods, products, instructions, or ideas contained in the material herein.

\section{Library of Congress Cataloging-in-Publication Data}

A catalog record for this book is available from the Library of Congress

\section{British Library Cataloguing-in-Publication Data}

A catalogue record for this book is available from the British Library

ISBN: 978-0-12-816897-4

For information on all Elsevier publications visit our website at https://www.elsevier.com/books-and-journals

Publisher: Matthew Deans

Acquisition Editor: Edward Payne

Editorial Project Manager: John Leonard

Production Project Manager: R.Vijay Bharath

Cover Designer: Greg Harris

Typeset by TNQ Technologies

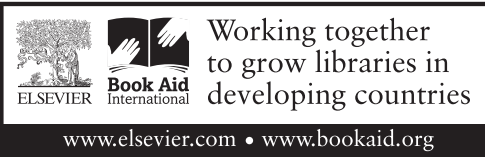




\section{Contents}

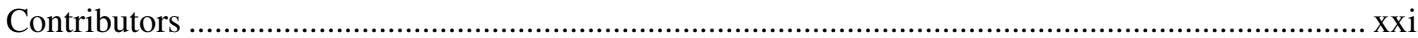

CHAPTER 1 Introduction of biopolymers: food and biomedical applications ........1

Dilshad Qureshi, Suraj Kumar Nayak, Arfat Anis, Sirsendu S. Ray,

Doman Kim, Thi Thanh Hanh Nguyen and Kunal Pal

1. Introduction

2. Cross-linking methods employed to design biopolymer-based polymeric architectures

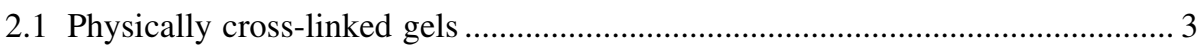

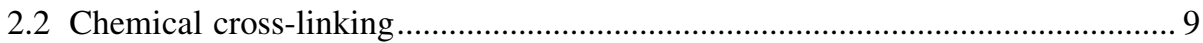

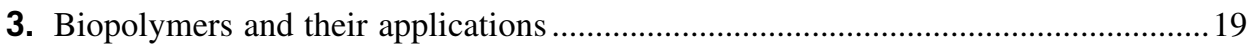

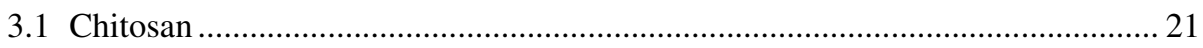

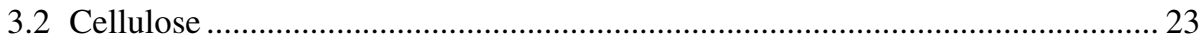

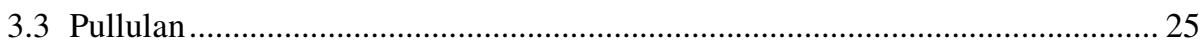

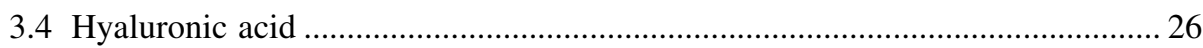

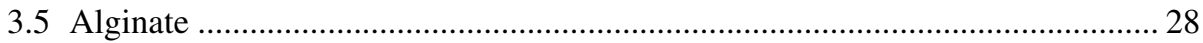

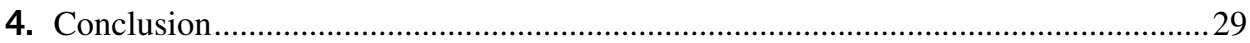

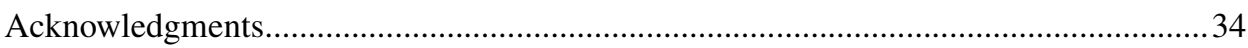

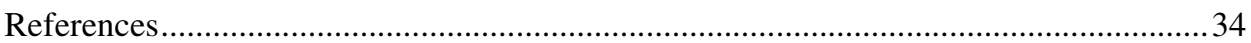

CHAPTER 2 Enzymatic synthesis of flavonoid glucosides and their biochemical characterization...................................................47

Thi Thanh Hanh Nguyen, Juhui Jin, Iis Septiana, Dilshad Quereshi,

Kunal Pal and Doman Kim

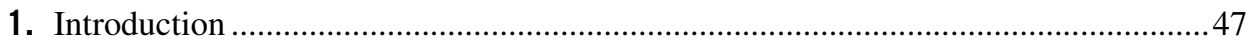

2. Enzymatic synthesis of glycosylated flavonoids ....................................................... 48

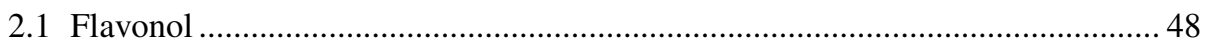

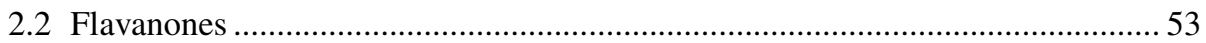

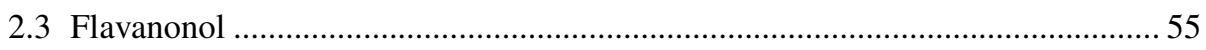

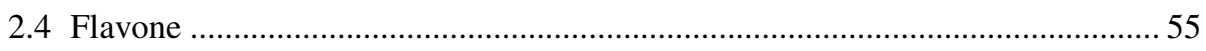

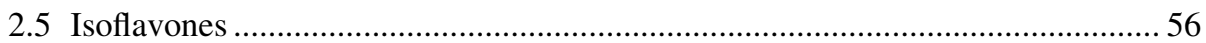

2.6 Physical and biological characterization of glycosylated flavonoids................. 57

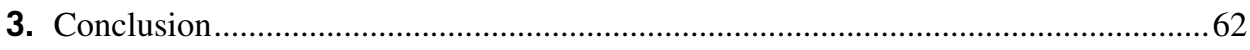

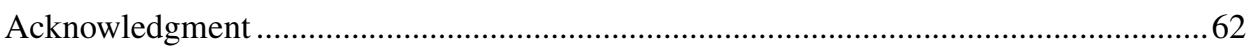

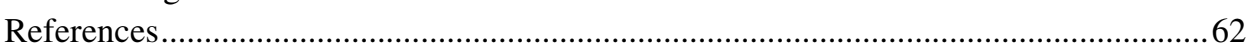

CHAPTER 3 Fish gelatin: molecular interactions and applications ...................67 Donghwa Chung

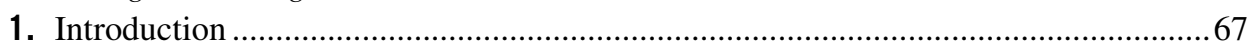

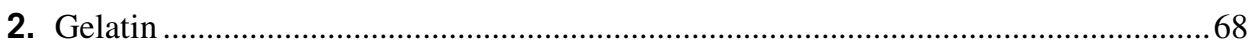


3. Fish gelatin 69

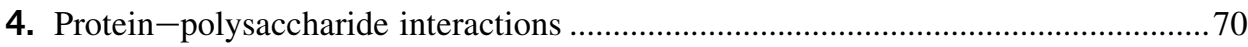

5. Molecular interactions of fish gelatin with polysaccharides.................................. 71

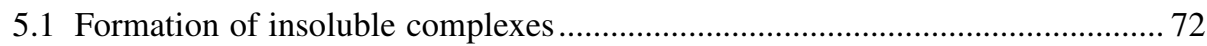

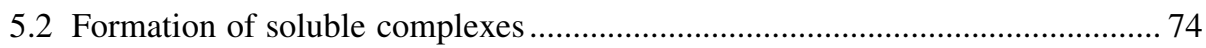

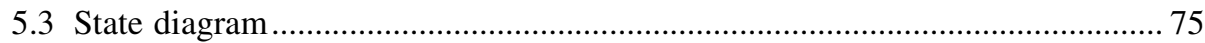

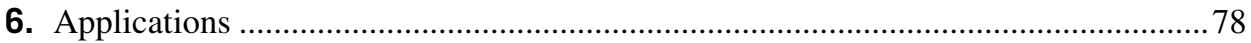

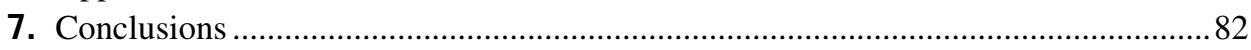

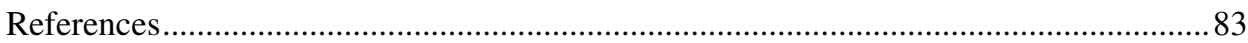

CHAPTER 4 Peptides as biopolymers - past, present, and future ....................... 87

Advaita Ganguly, Kumakshi Sharma and Kaustav Majumder

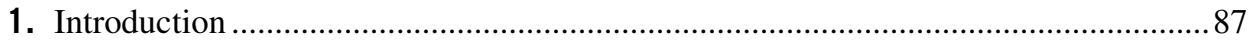

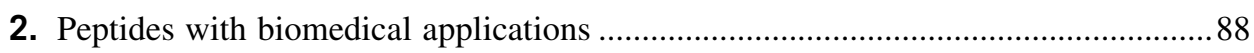

2.1 Therapeutic peptides and biopolymers ..................................................... 90

2.2 Biopolymers and peptides targeting the cardiovascular system....................... 91

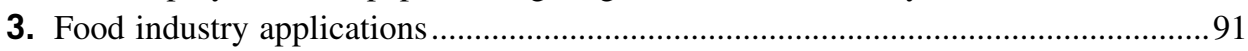

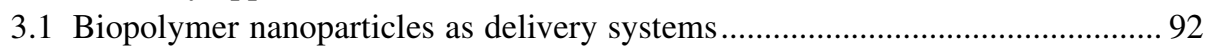

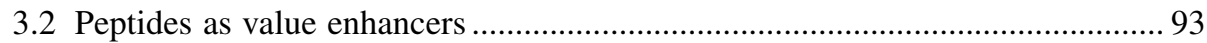

3.3 Biopolymers in food processing and packaging............................................... 93

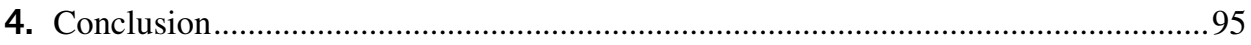

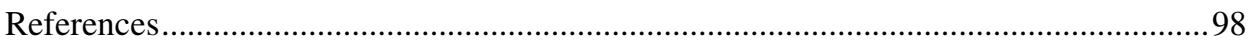

\section{CHAPTER 5 Microbial production of biopolymers with potential}

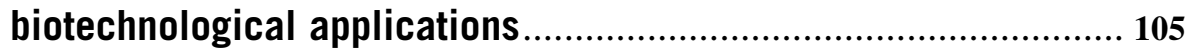

Madan L. Verma, Sanjeev Kumar, John Jeslin and Navneet Kumar Dubey

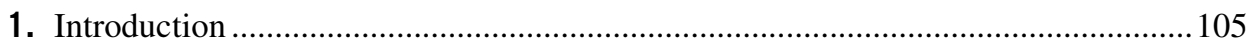

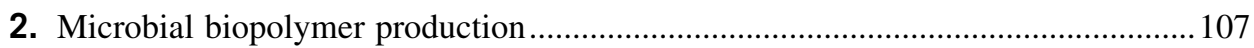

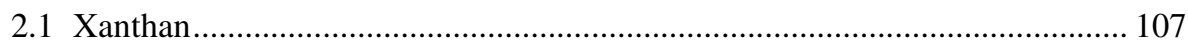

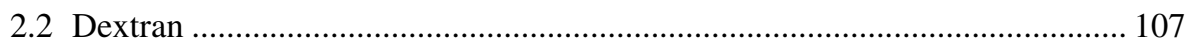

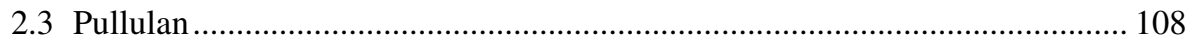

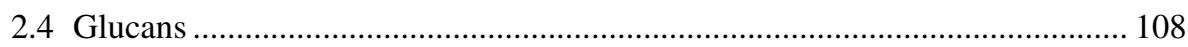

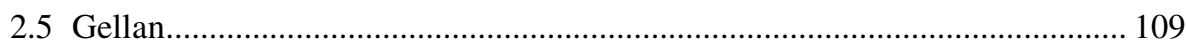

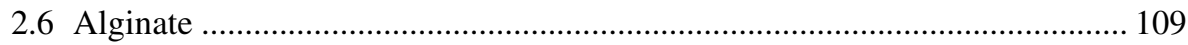

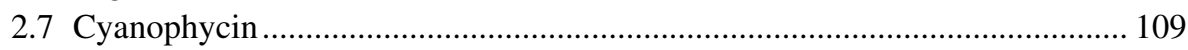

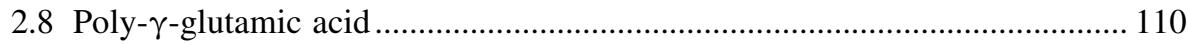

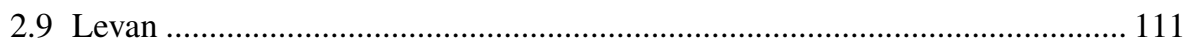

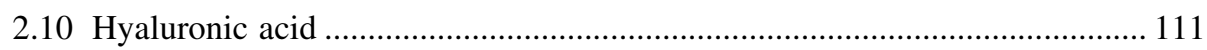

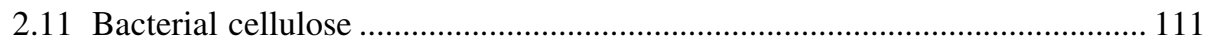

2.12 Organic acid fermentation for polymer synthesis ......................................... 112

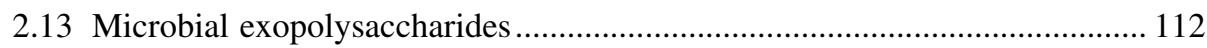

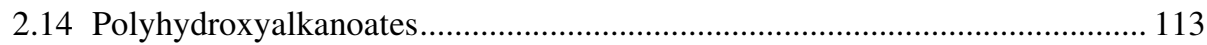


3. Biosynthesis of microbial polyhydroxyalkanoates

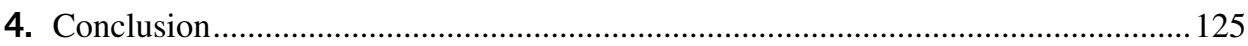

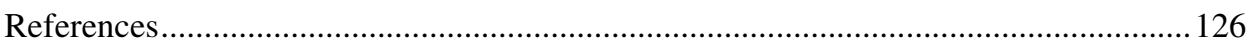

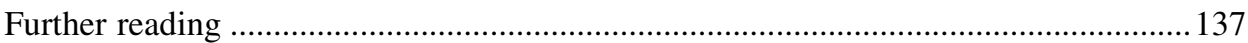

\section{CHAPTER 6 Animal-derived biopolymers in food and biomedical}

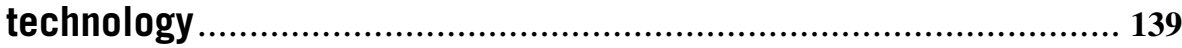
Varsha Wankhade

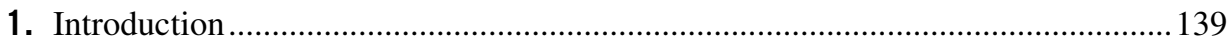

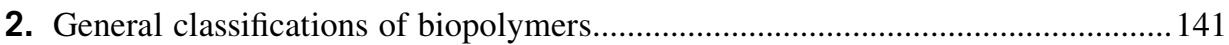

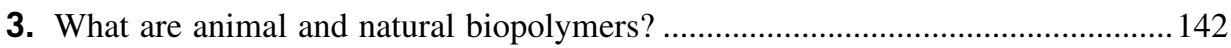

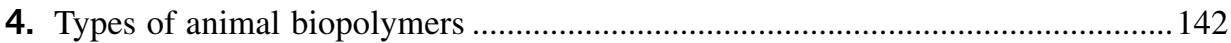

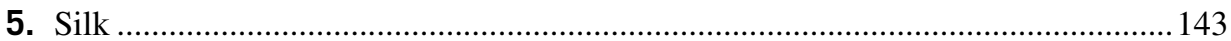

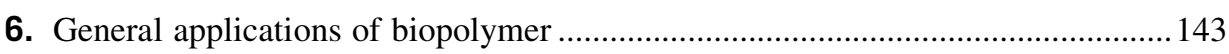

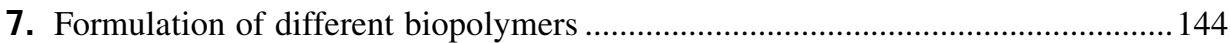

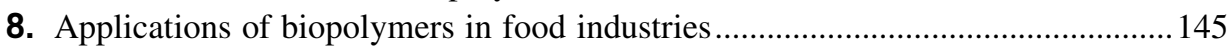

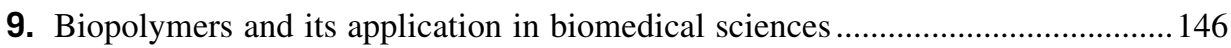

10. Some environmental benefits of use of biopolymer .............................................. 149

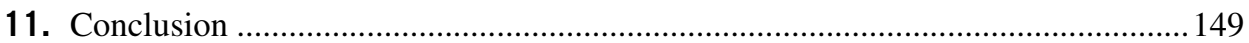

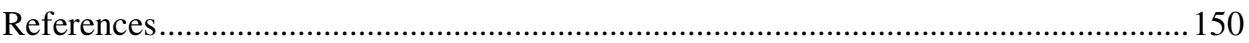

\section{CHAPTER 7 Application of CRISPR technology to the high production of}

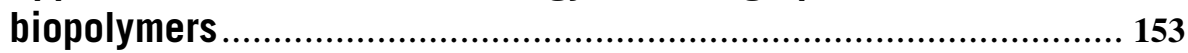

Hyo Jin Kim and Timothy Lee Turner

1. Introduction

2. Application of CRISPR/Cas9 in various research................................................. 153

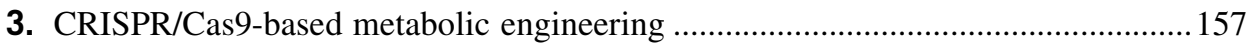

4. CRISPR/Cas9-based genome editing in biopolymer production from prokaryotes

5. CRISPR/Cas9-based genome editing in biopolymer production from eukaryotes.

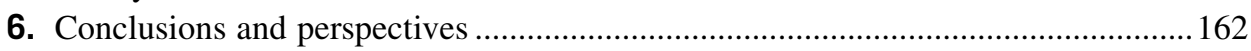

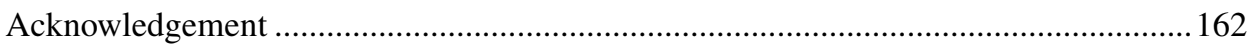

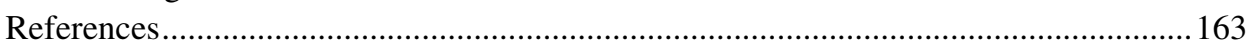

CHAPTER 8 Biomedical and food applications of biopolymer-based

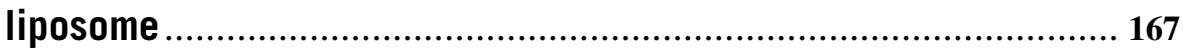

Sayantani Dutta, Jeyan A. Moses and C. Anandharamakrishnan

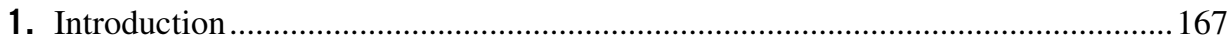

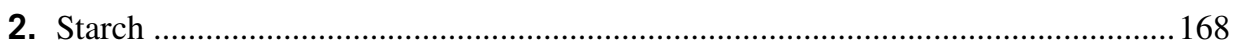

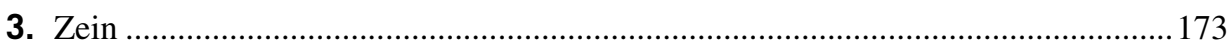

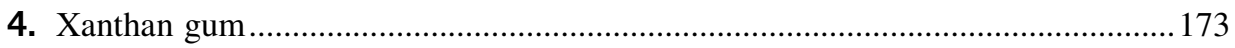




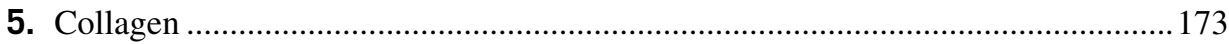

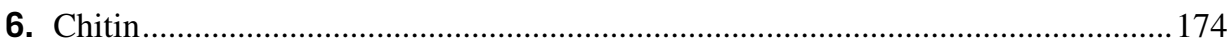

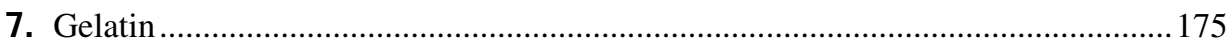

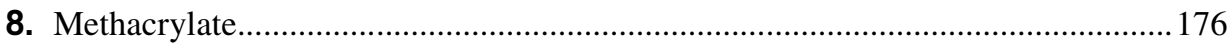

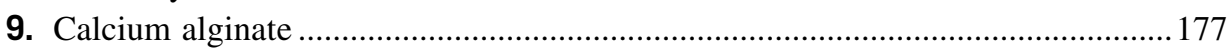

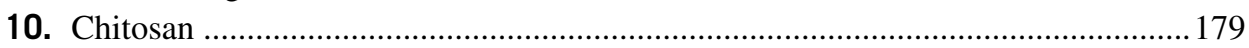

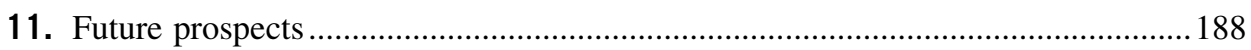

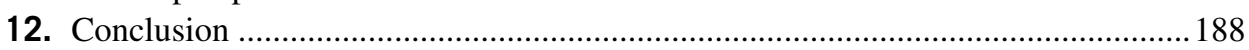

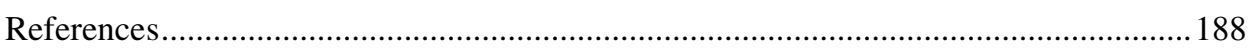

CHAPTER 9 Nanosized magnetic particles for cancer theranostics .................. 193

Sadaf Hameed and Pravin Bhattarai

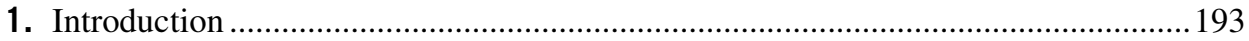

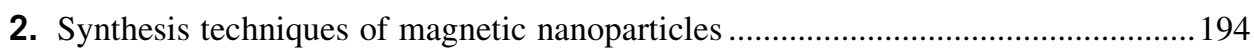

3. Physiochemical properties of MNPs ....................................................................... 195

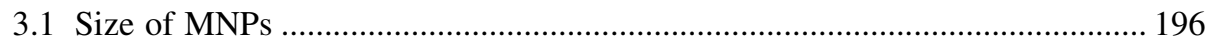

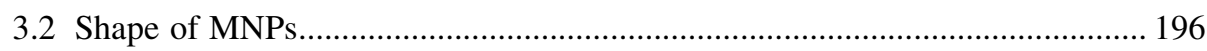

3.3 Surface properties and biopolymer-functionalized MNPs ............................ 197

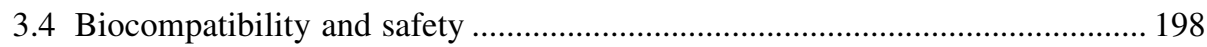

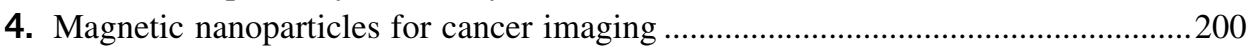

5. Magnetic nanoparticles for cancer therapy ….......................................................202

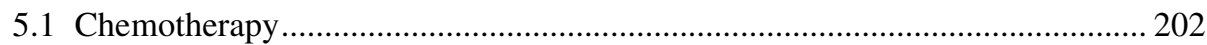

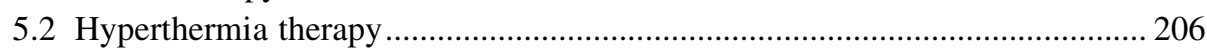

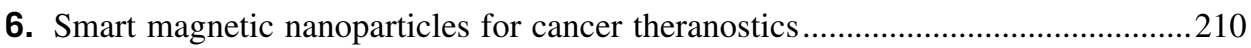

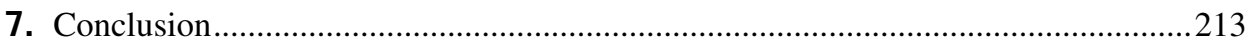

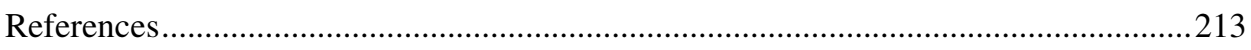

CHAPTER 10 Core-shell biopolymer nanoparticles ......................................... 221 Yue Zhang and Lei Wang

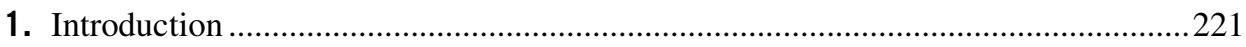

2. Materials used for core-shell nanoparticles .....................................................222

3. Methods involved in the formation of core-shell nanoparticles.............................225

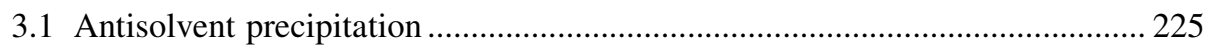

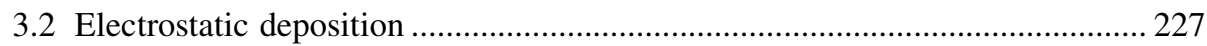

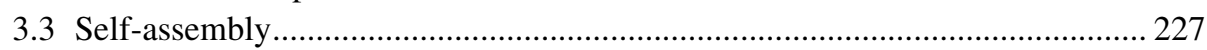

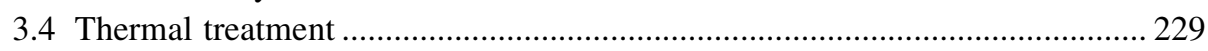

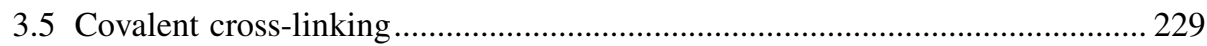

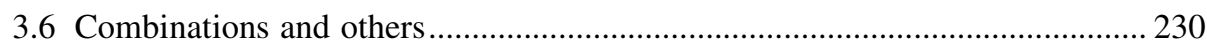

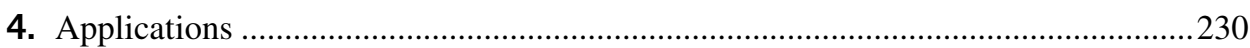

4.1 Delivery of small molecular drugs and nutraceuticals ................................... 230

4.2 Delivery of peptides and proteins ............................................................ 231 


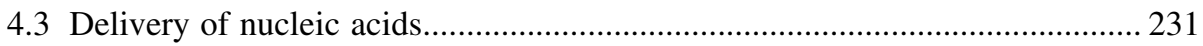

5. Current issues and future development ................................................................... 231

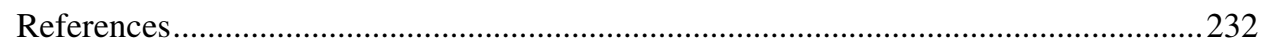

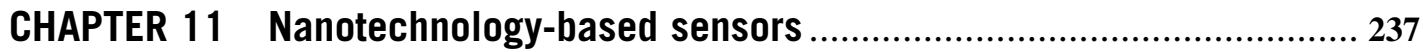

Sushant Prajapati, Bhagyashree Padhan, B. Amulyasai and Angana Sarkar

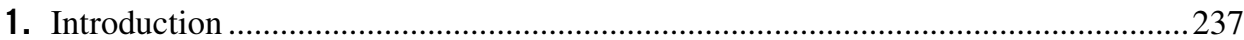

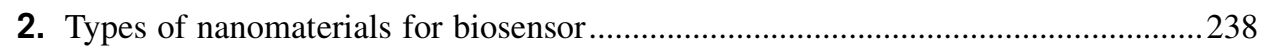

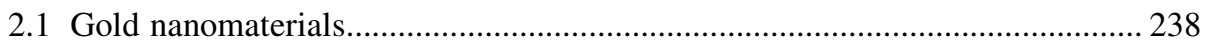

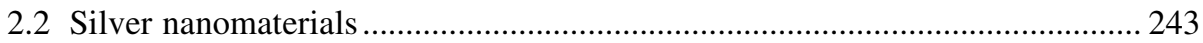

2.3 Carbon nanostructures ............................................................................... 243

2.4 Silicon nanomaterial ................................................................................... 244

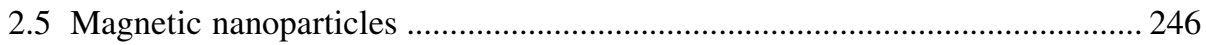

2.6 Biopolymers-based nanosensors .................................................................... 248

3. Properties of nanomaterials used for detection in biosensors...................................248

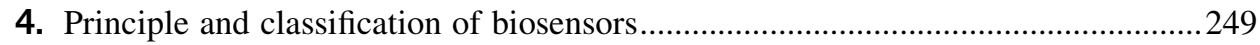

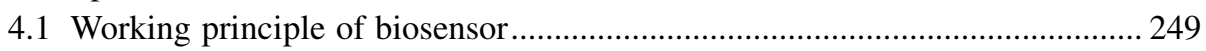

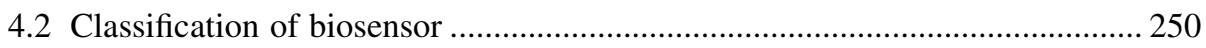

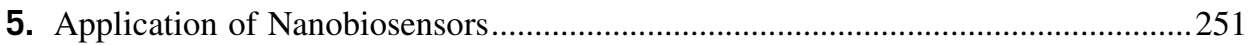

6. Pros and cons of biosensors and strategy to overcome.............................................2. 256

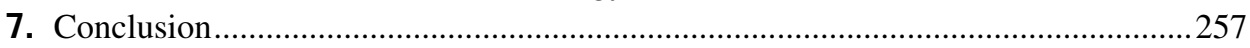

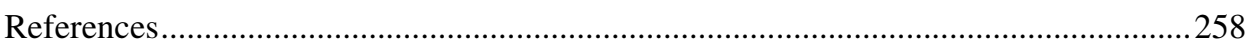

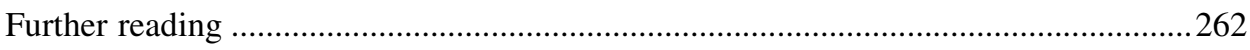

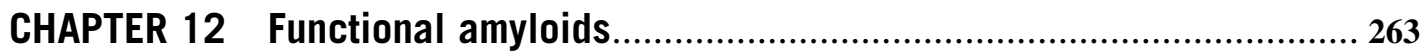
Nandini Sarkar

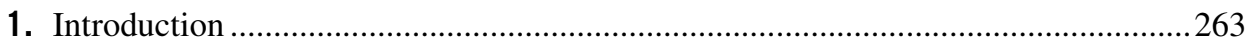

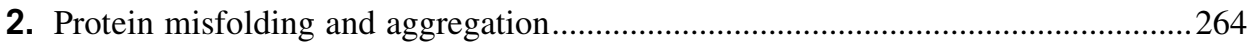

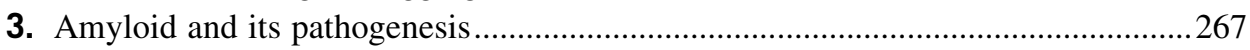

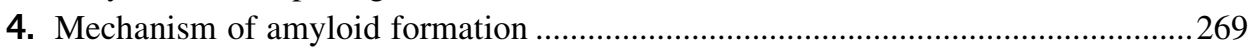

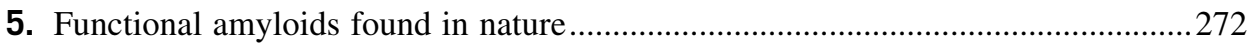

5.1 As structural components ...................................................................... 272

5.2 As regulatory factors in several biochemical pathways ................................. 273

5.3 As scaffolds for storage and release of proteins............................................ 273

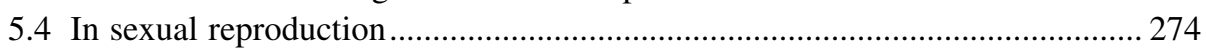

5.5 As molecular chaperones ............................................................................ 274

6. How toxicity is prevented with functional amyloids?............................................274

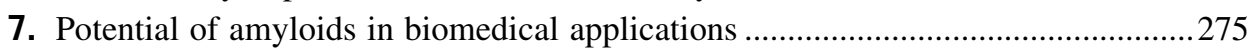

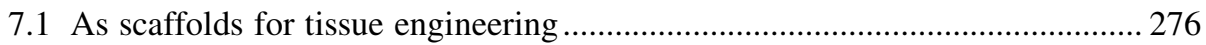

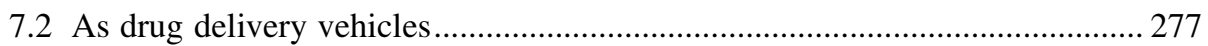

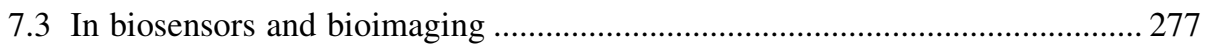

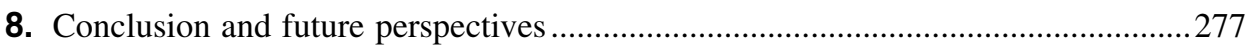

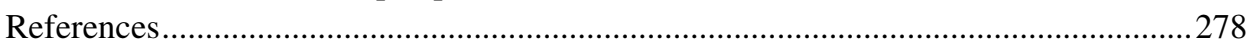

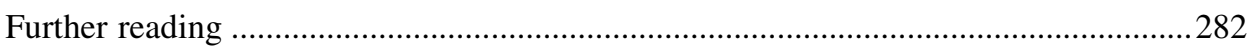




\section{CHAPTER 13 Lipid-derived renewable amphiphilic nanocarriers for drug delivery, biopolymer-based formulations: biomedical and food applications}

Muhammad Arshad, Rehan Ali Pradhan, Muhammad Zubair and Aman Ullah

1. Introduction 283

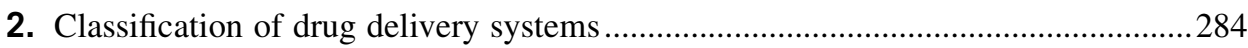

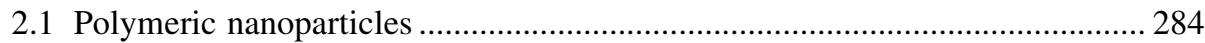

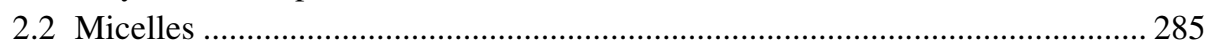

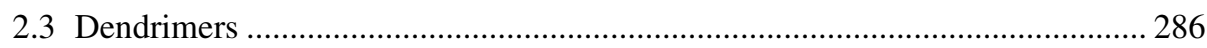

3. Emulsions-based drug delivery systems ...............................................................28

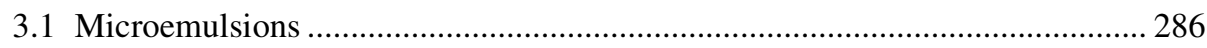

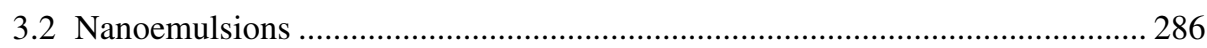

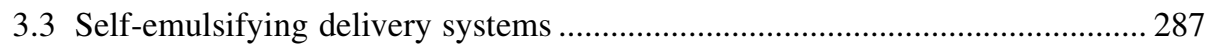

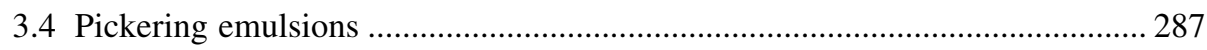

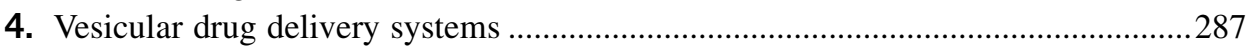

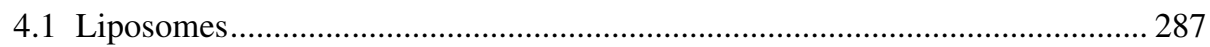

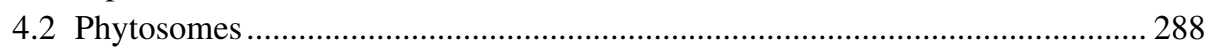

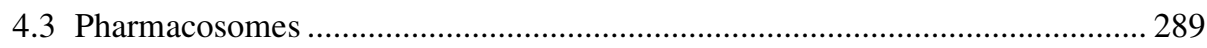

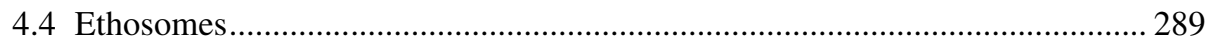

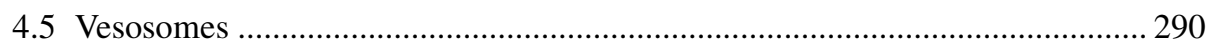

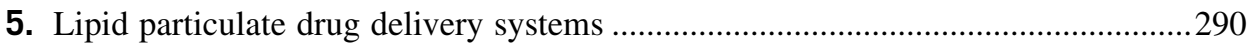

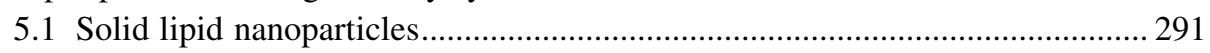

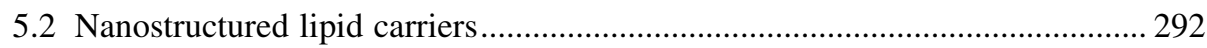

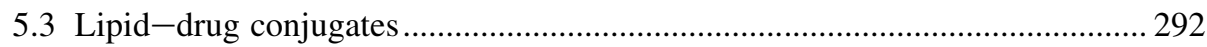

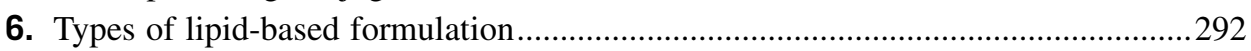

6.1 Processing techniques for lipid formulations .............................................. 293

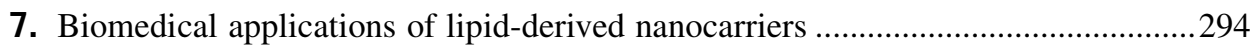

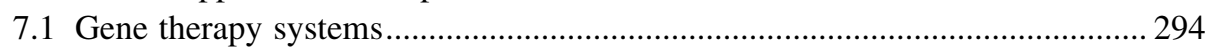

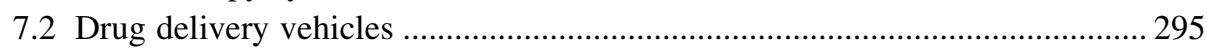

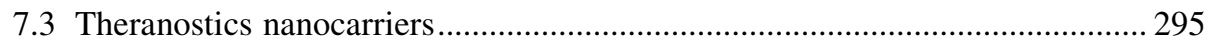

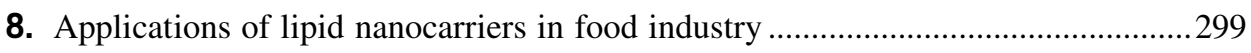

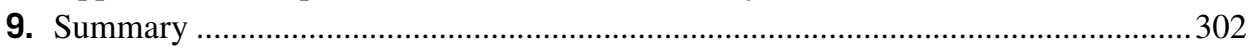

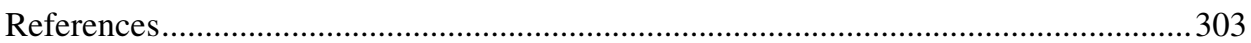

\section{CHAPTER 14 Nanoencapsulation of nutraceutical ingredients ......................... 311}

M. Maria Leena, L. Mahalakshmi, Jeyan A. Moses and

C. Anandharamakrishnan

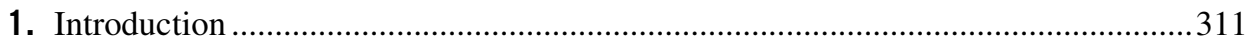

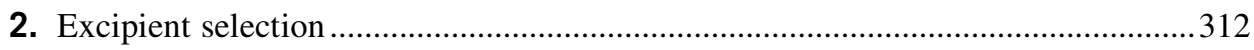

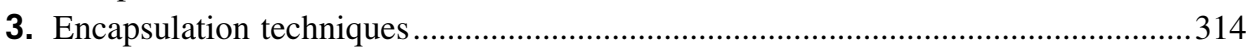

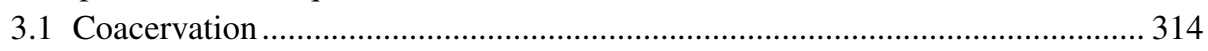


3.2 Electrospraying/spinning

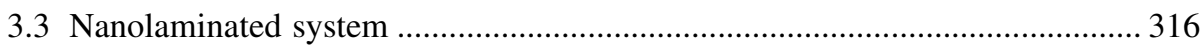

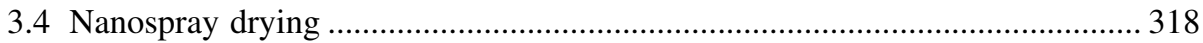

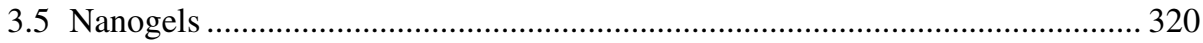

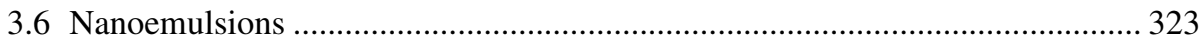

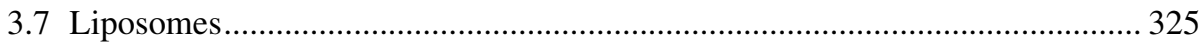

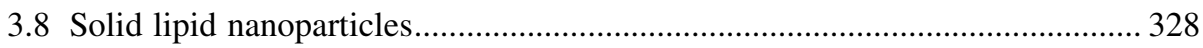

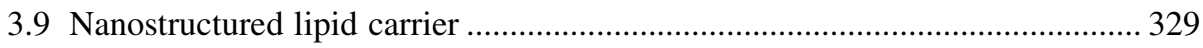

4. Impact of encapsulation on characteristics of nutraceutical compound .....................331

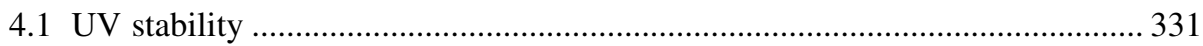

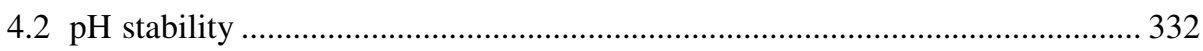

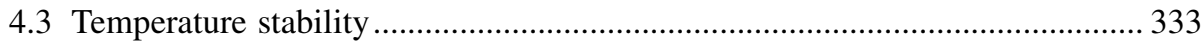

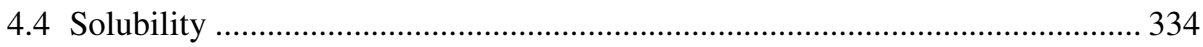

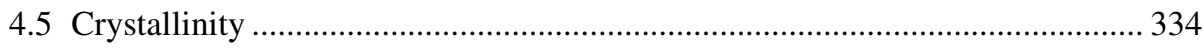

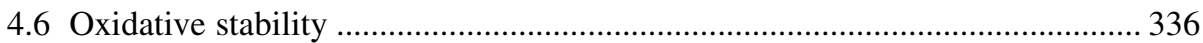

5. Mechanism of release of bioactive compounds from encapsulated matrix..............337

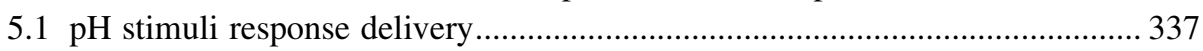

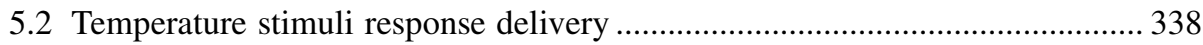

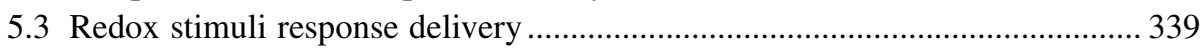

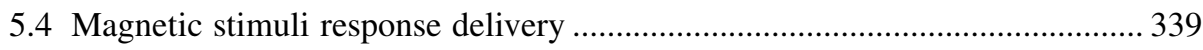

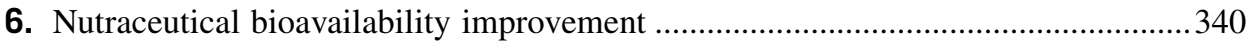

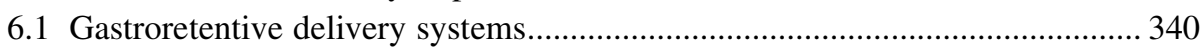

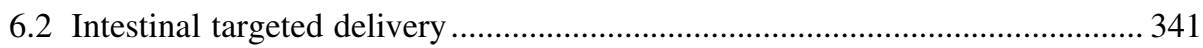

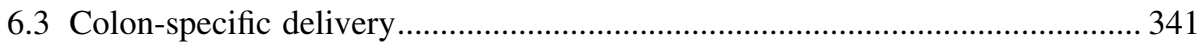

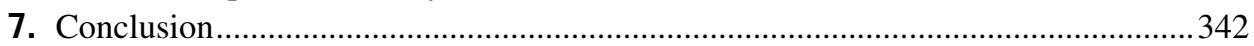

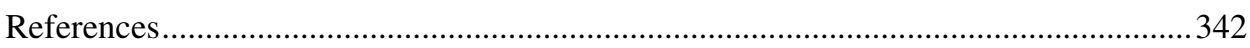

\section{CHAPTER 15 Nutraceutical encapsulation and delivery system for type 2} diabetes mellitus ...................................................................... 353

Navneet Kumar Dubey, Abhinay Kumar Singh, Rajni Dubey and Win-Ping Deng

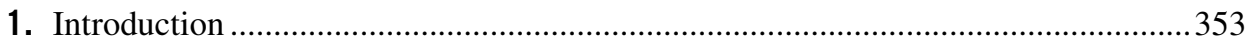

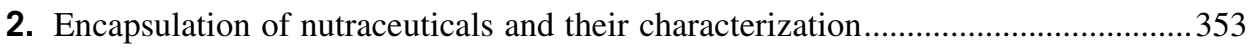

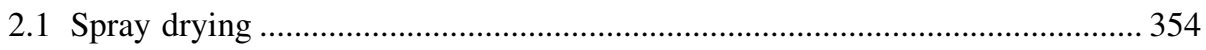

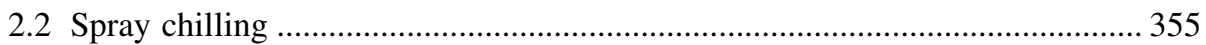

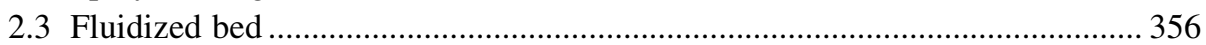

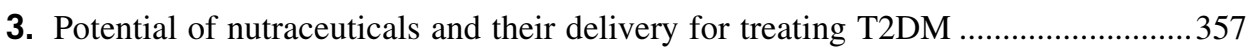

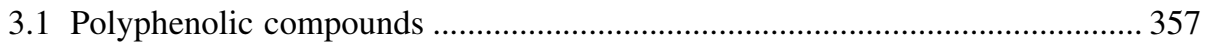

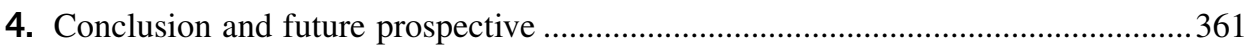

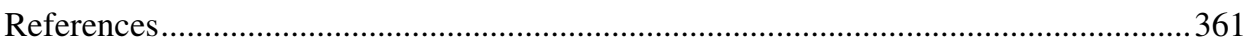


1. Introduction . 365

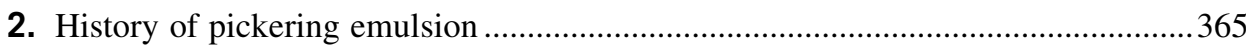

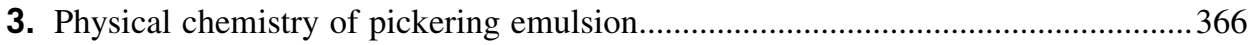

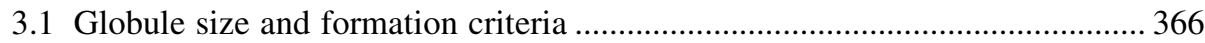

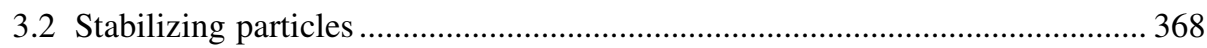

3.3 Stable emulsion formation by adsorbed solid particle ................................. 371

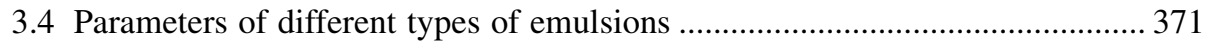

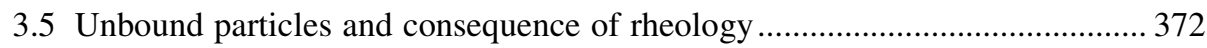

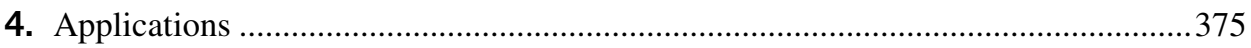

4.1 Potential application to the life science and drug delivery ........................... 375

4.2 Application in material science using polymerization template ........................ 376

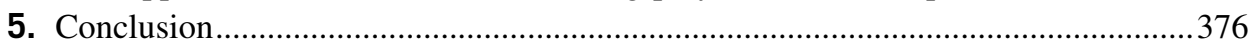

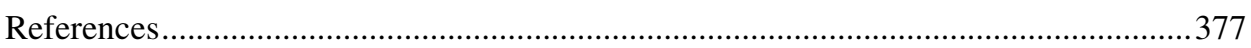

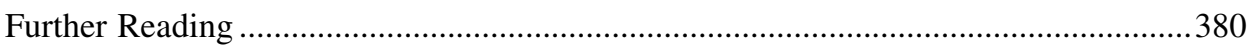

\section{CHAPTER 17 Microencapsulation of bioactive compounds and enzymes} for therapeutic applications......................................................... 381

Ragini G Bodade and Anand G Bodade

1. Introduction

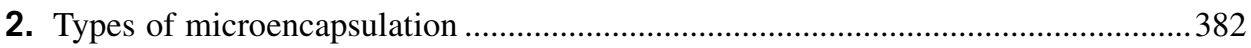

3. Microencapsulation of bioactive compounds and bioactive extracts..........................383

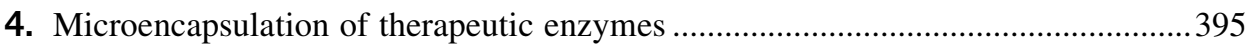

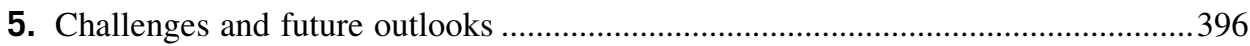

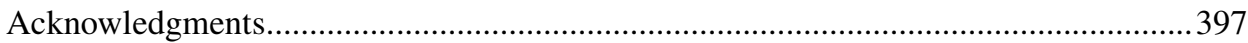

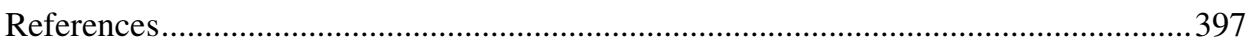

\section{CHAPTER 18 Rice husk silica for the stabilization of food-grade} oil-in-water (O/W) emulsions ...................................................... 405 Lanny Sapei

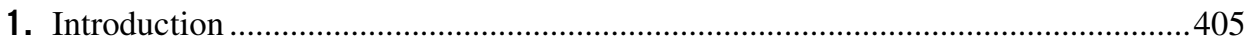

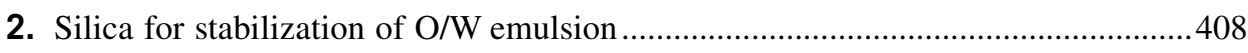

3. Effect of emulsifier addition combined with rice husk silica in stabilizing $\mathrm{O} / \mathrm{W}$ emulsion.

3.1 Addition of lecithin in the oil phase ........................................................... 410

3.2 Addition of Tween-20 in the aqueous phase ............................................... 412

4. Effect of $\mathrm{pH}$ of outer continuous phase on the stability of $\mathrm{O} / \mathrm{W}$ emulsion stabilized with rice husk silica...

5. Effect of storage temperature on the stability of $\mathrm{O} / \mathrm{W}$ emulsion stabilized with rice husk silica....

6. Kinetics study on the stability of $\mathrm{O} / \mathrm{W}$ emulsion stabilized with rice husk silica ..416 
Acknowledgments. 420

References

Saumya Agarwal, Monjurul Hoque, Nupur Mohapatra, Irshaan Syed,

Chanda Vilas Dhumal, Subhadeep Bose, Prasanta Kumar Biswas,

Padmaja Kar, Nisarani Bishoyi and Preetam Sarkar

1. Introduction

2. Hydrocolloid-based films incorporated with essential oils .....................................426

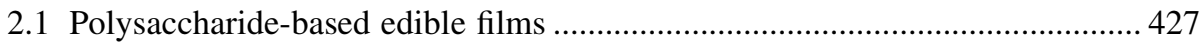

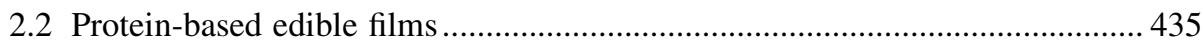

3. Composite films incorporated with essential oils......................................................439

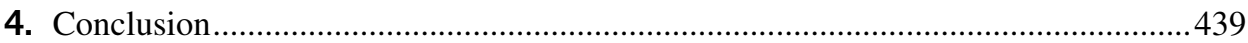

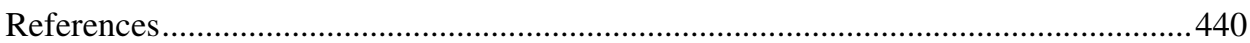

CHAPTER 20 Tamarind seed polysaccharide: unique profile of properties and applications .................................................................... 445

Kazuhiko Yamatoya, Akira Tabuchi, Yumewo Suzuki and Hiroyuki Yamada

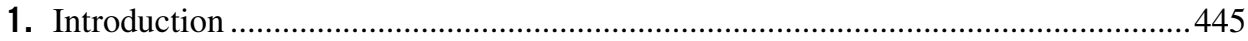

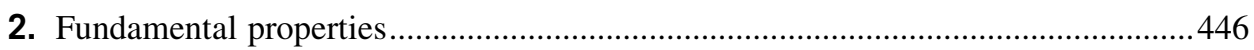

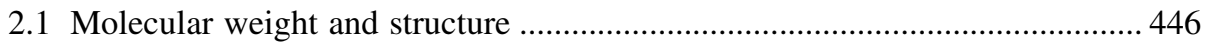

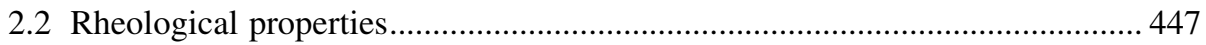

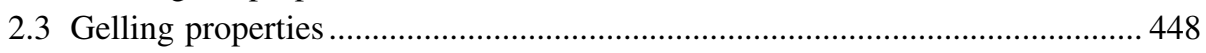

2.4 Emulsion stabilizing and emulsification property .......................................... 450

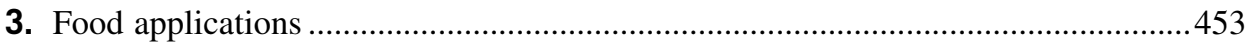

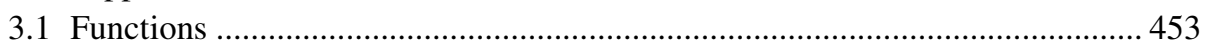

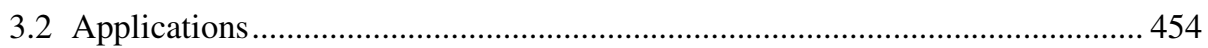

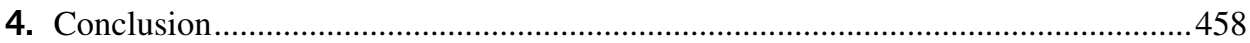

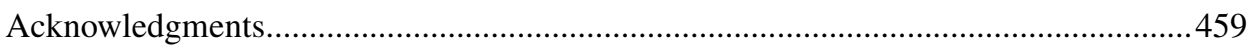

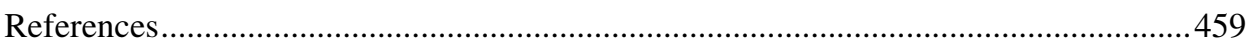

\section{CHAPTER 21 Thermomechanical and surface morphology of} biopolymer-nanoparticle composite films................................ 463 Jasim Ahmed

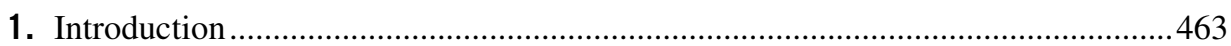

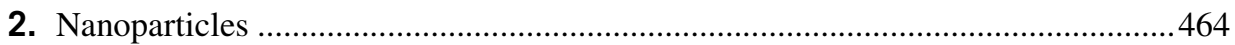

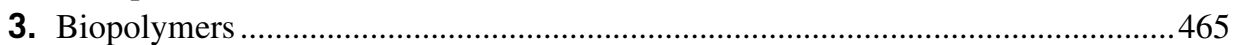

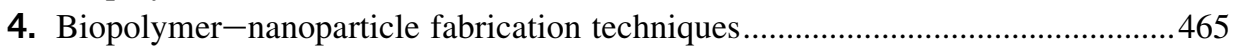

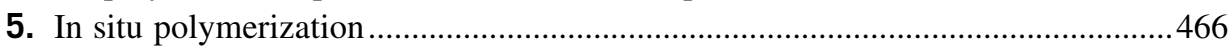

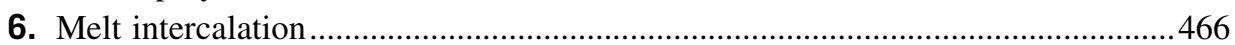

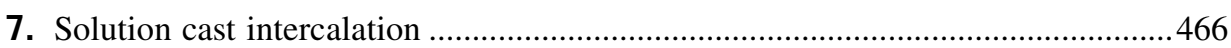

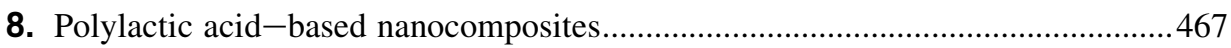


9. Rheology of polylactic acid-based nanocomposites 467

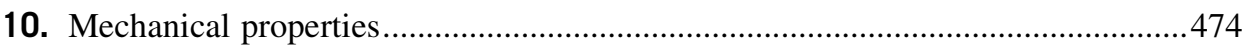

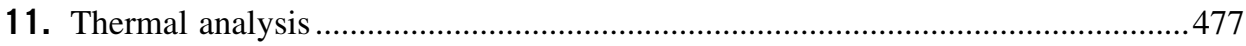

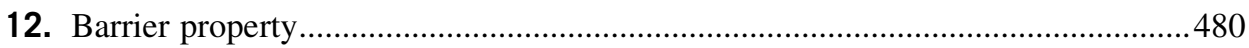

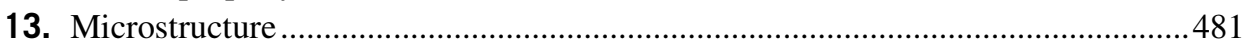

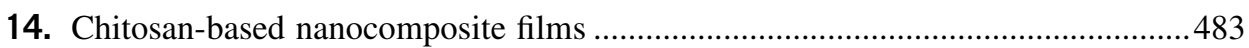

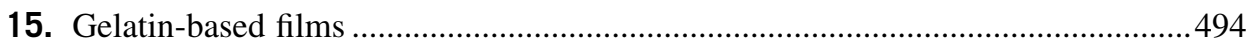

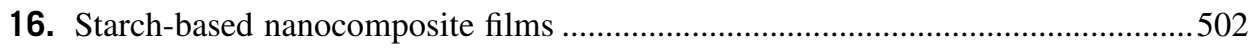

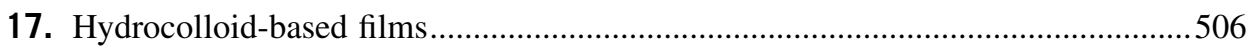

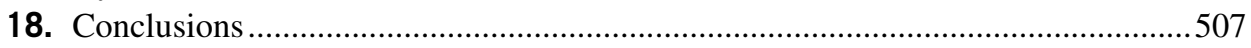

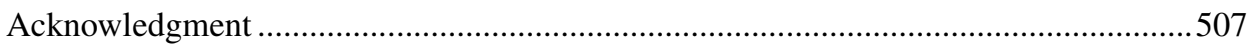

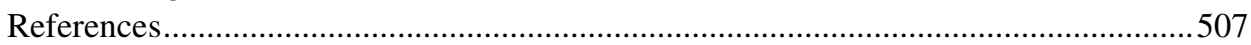

\section{CHAPTER 22 Natural and bioderived molecular gelator-based oleogels} and their applications ............................................................... 513

Sai S. Sagiri and K.J. Rao

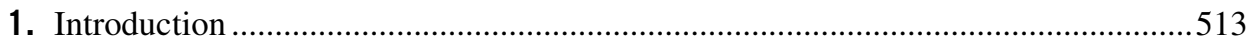

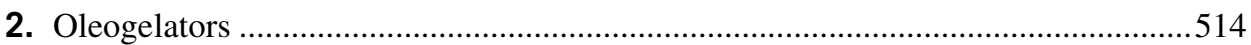

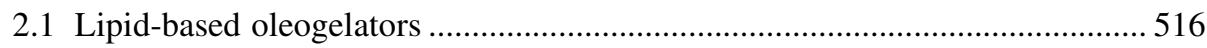

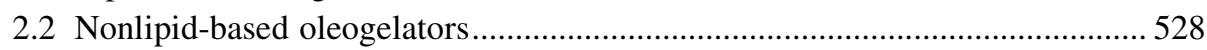

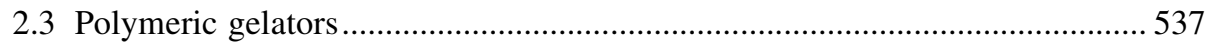

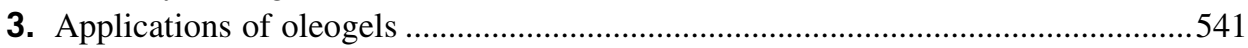

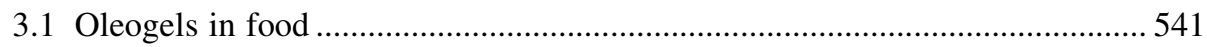

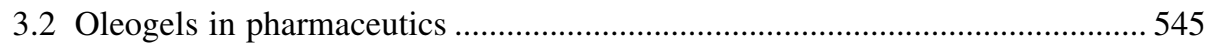

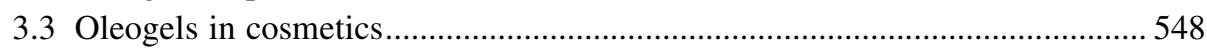

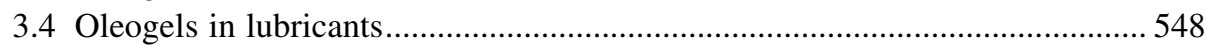

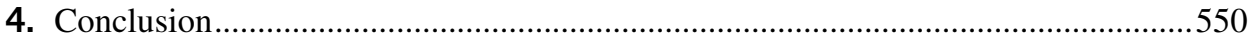

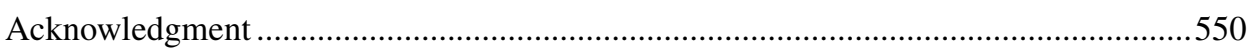

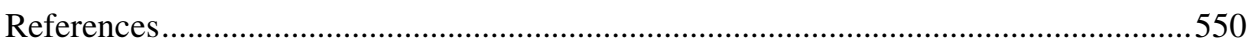

CHAPTER 23 Hydrogels as biodegradable biopolymer formulations ................561 Margaret $O$. Ilomuanya

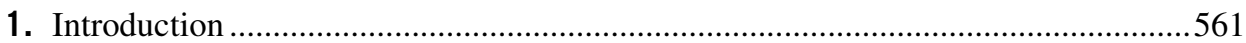

1.1 Hydrogels as biopolymer-based formulations ................................................. 561

1.2 Hydrogel classification based on structure and biomaterial classification........ 562

2. Polysaccharide-based hybrid biopolymer hydrogels ...............................................563

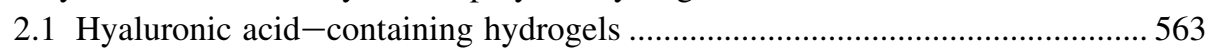

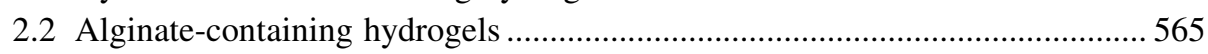

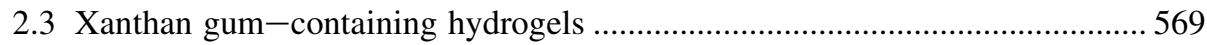

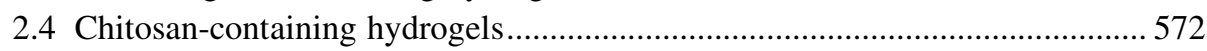

2.5 Protein extracellular matrix - containing hydrogels ...................................... 574 


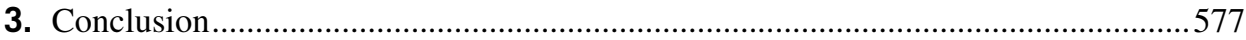

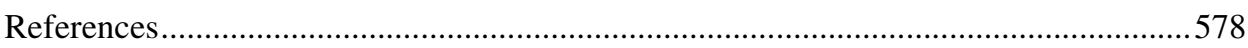

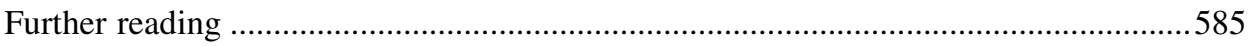

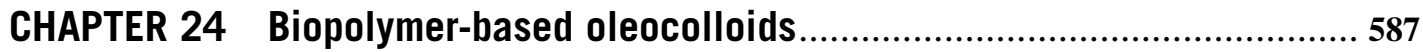
Ashok R. Patel

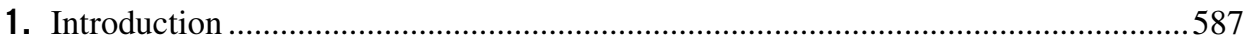

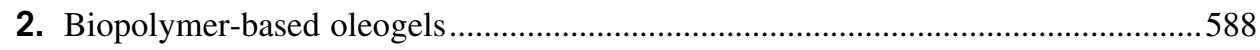

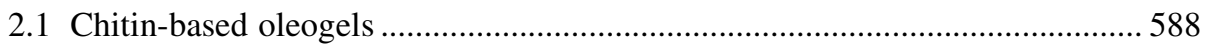

2.2 Oleogels prepared from surface-active biopolymers through colloid-templated approaches............................................................................ 589

2.3 Gels prepared from protein hydrogels via stepwise solvent exchange

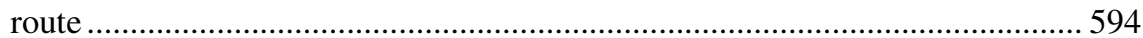

2.4 Gel prepared from aerogel-templated approach ................................................59

2.5 Gel prepared from emulsion-encapsulation approach ……………………...... 595

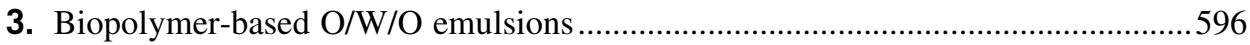

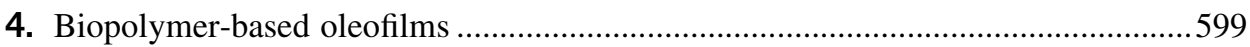

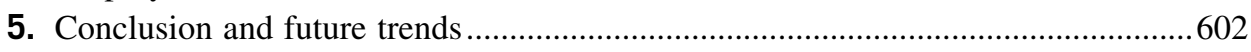

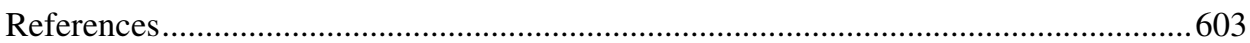

CHAPTER 25 Gum-based hydrogels in drug delivery ......................................605

Amit Kumar Nayak, Md Saquib Hasnain, Kunal Pal, Indranil Banerjee and Dilipkumar Pal

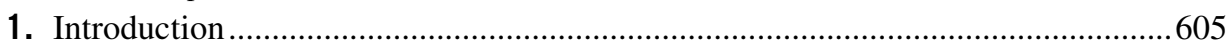

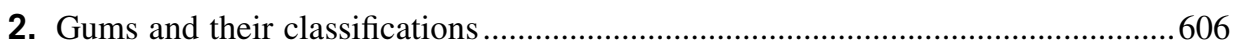

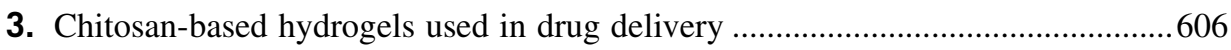

4. Alginate-based hydrogels used in drug delivery ..................................................610

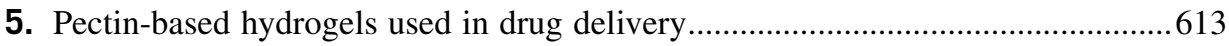

6. Gellan gum-based hydrogels used in drug delivery...............................................620

7. Tamarind gum-based hydrogels used in drug delivery ..........................................623

8. Sterculia gum-based hydrogels used in drug delivery ...........................................626

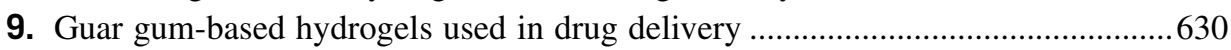

10. Locust bean gum-based hydrogels used in drug delivery........................................633

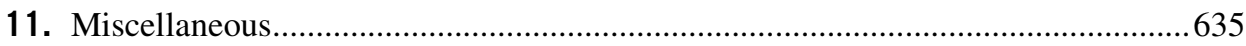

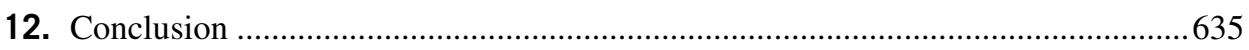

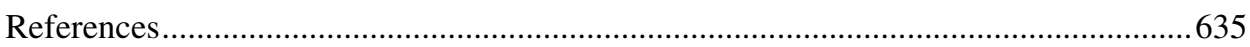

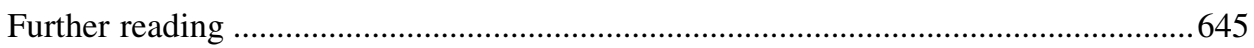


CHAPTER 26 Implant surface modification strategies through antibacterial and bioactive components

Agustin Wulan Suci Dharmayanti, Rajni Dubey, Navneet Kumar Dubey and Win-Ping Deng

1. Introduction 647

2. Response of cells and tissues to implant materials ................................................648

2.1 Bone tissue: the most fundamental unit supporting implant..............................648 648

2.2 Effect of environmental factors to implant performance ................................651

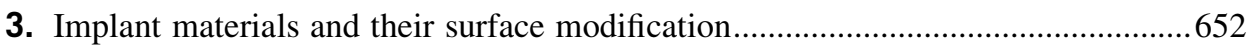

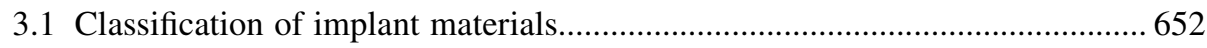

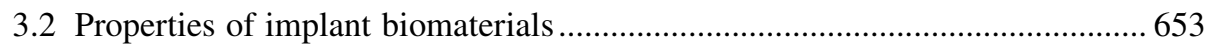

3.3 Technique and methods for surface modification of implant materials............ 655

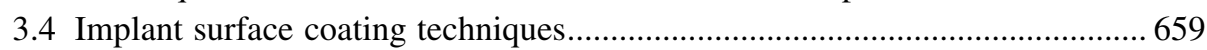

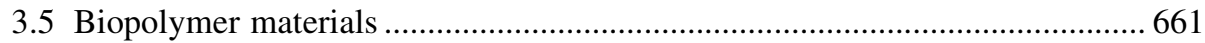

3.6 Antimicrobial activity of biopolymer implant coating ................................... 662

3.7 Methods for biopolymer processing as surface modification and

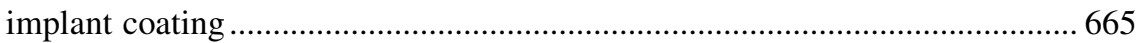

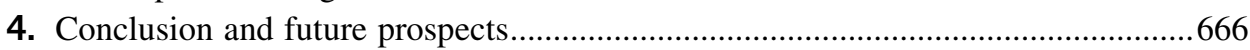

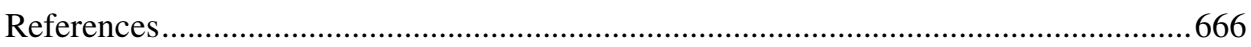

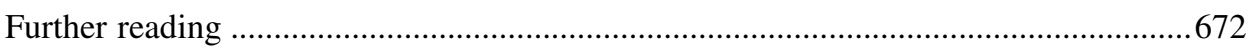

CHAPTER 27 Edible films and coatings: an update on recent advances...........675

Navneet Kumar Dubey and Rajni Dubey

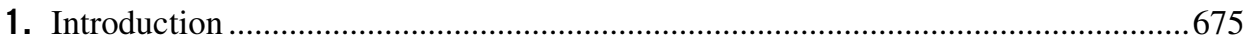

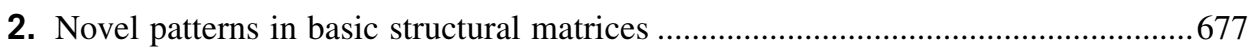

2.1 New trends in polysaccharides-based edible films .........................................6 677

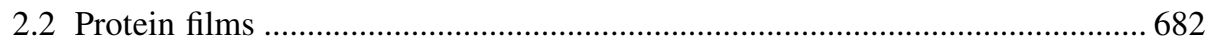

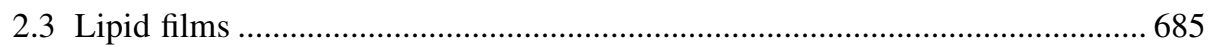

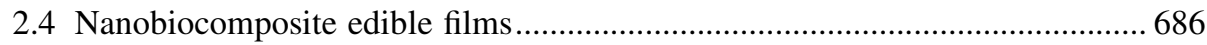

3. Recent advances in the applications of edible films ...............................................68

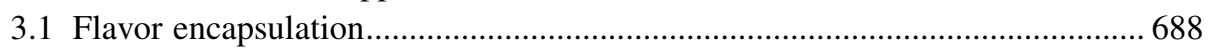

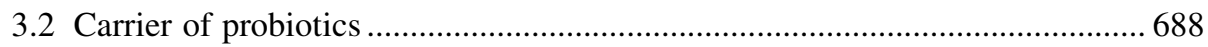

3.3 Carriers of antioxidant and antimicrobial compounds ......................................60 690

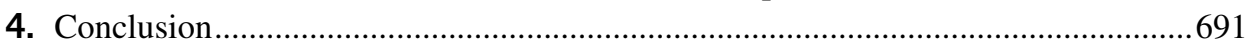

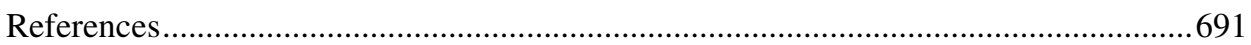

\section{CHAPTER 28 Rheology and tribology assessment of foods: a food oral}

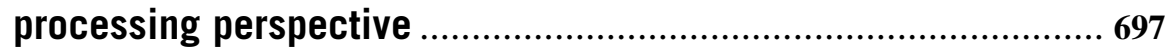

Rituja Upadhyay and Jianshe Chen

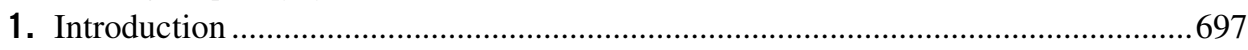

2. Rheology: basic understanding of the tests used in the food industry .....................698

2.1 Flow properties of fluid foods using rotational tests ...................................... 701

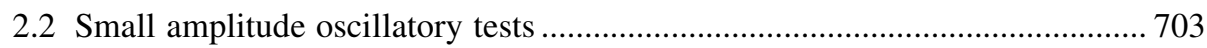




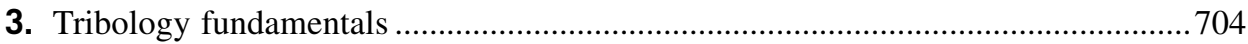

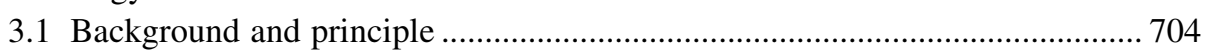

3.2 Tongue movements and role of saliva .......................................................... 707

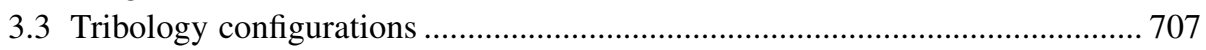

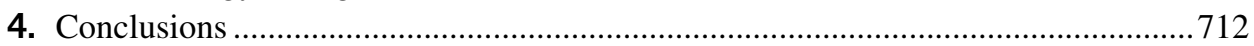

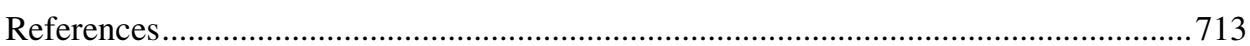

\section{CHAPTER 29 Biopolymer-based scaffolds: development and biomedical}

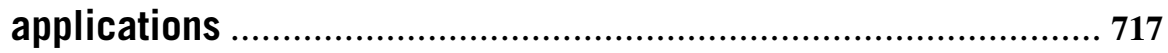

Ann Mary George, Sai Preetham Reddy Peddireddy, Goutam Thakur and Fiona Concy Rodrigues

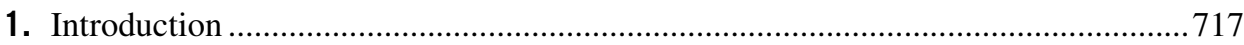

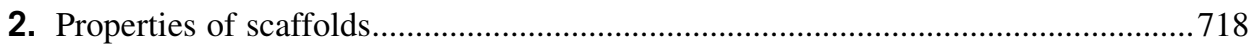

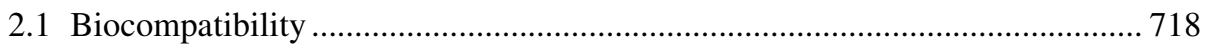

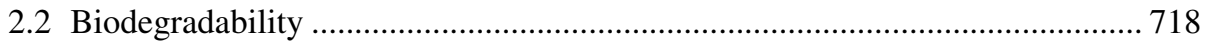

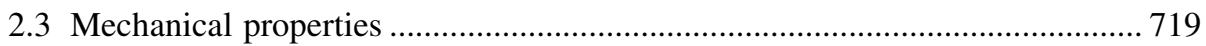

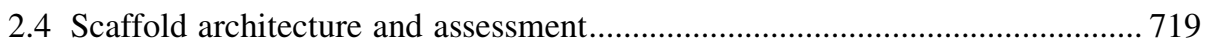

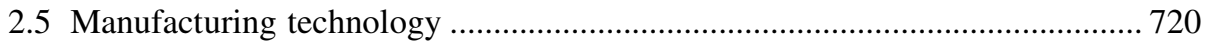

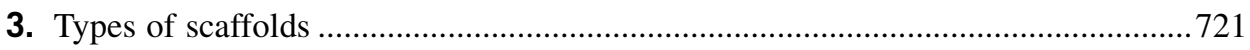

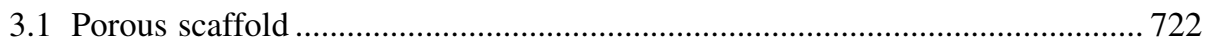

3.2 Microsphere scaffold ……………………………………………… 722

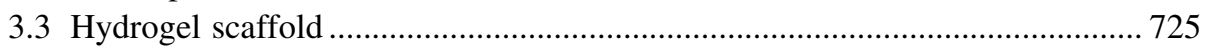

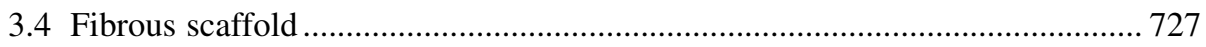

3.5 Polymer-bioceramic composite scaffold ................................................... 728

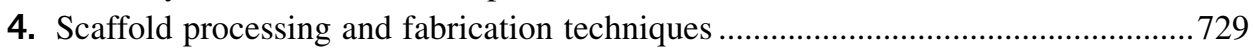

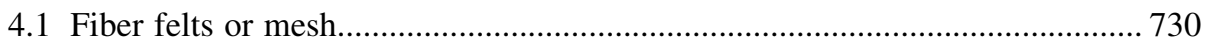

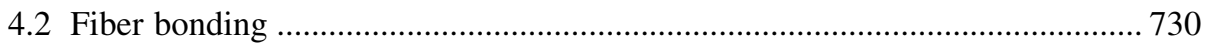

4.3 Solvent casting and particulate leaching ………………………………...... 732

4.4 Membrane lamination ................................................................................. 733

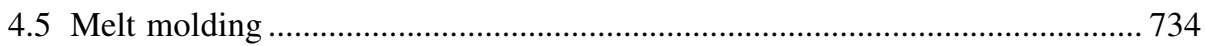

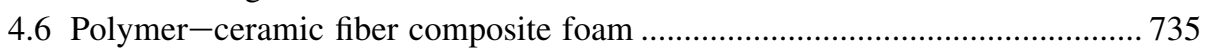

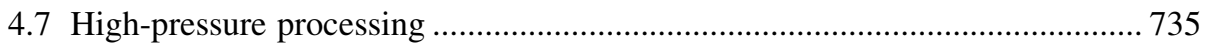

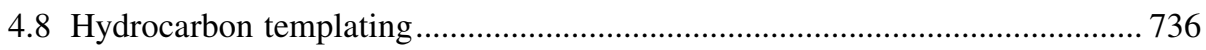

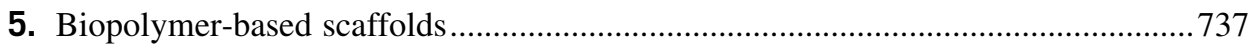

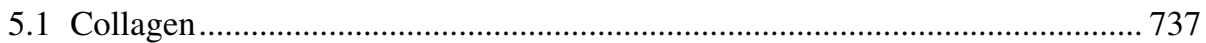

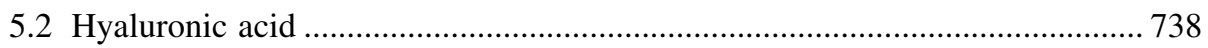

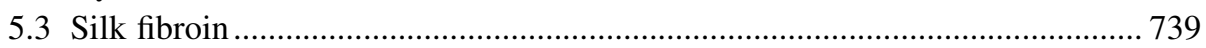

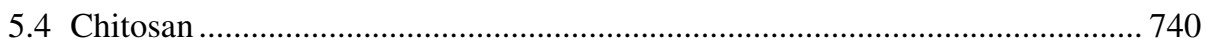

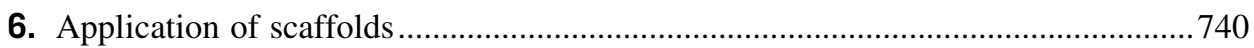

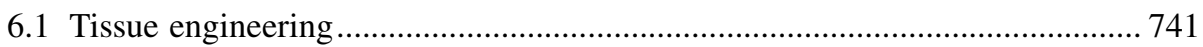

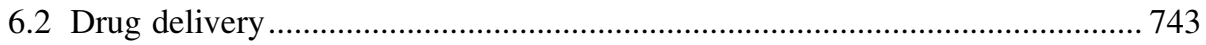




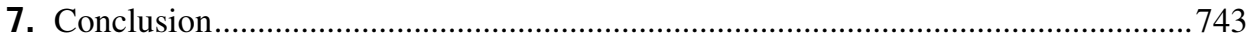

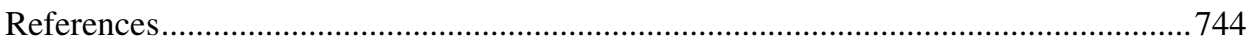

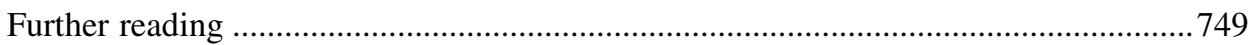

CHAPTER 30 Phenolic nanoconjugates and its application in food ................. 751

Rimpi Foujdar, Manav Bandhu Bera and Harish Kumar Chopra

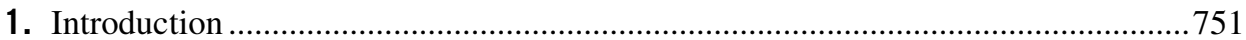

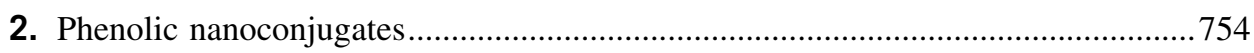

2.1 Phenols-polysaccharide nanoconjugates .......................................................... 755

2.2 Phenols-protein nanoconjugates ...................................................................... 755

2.3 Phenols-protein-polysaccharides nanoconjugates ………………………...... 758

2.4 Phenols-metal nanoconjugates ..................................................................... 758

3. Production techniques of phenolic nanoconjugates ………………………….......760

3.1 Noncovalent methods for phenolic nanoconjugates .......................................... 760

3.2 Covalent methods for phenolic nanoconjugates ……………………………..... 762

3.3 Physical methods for phenolic nanoconjugates ............................................... 763

4. Identification and characterization of phenolic nanoconjugates ................................764

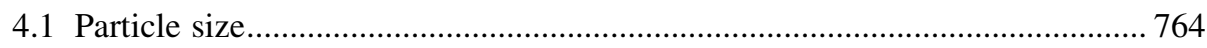

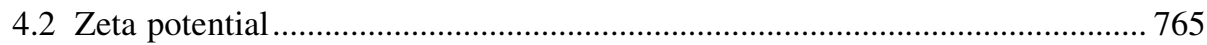

4.3 Scanning electron microscope ……………………………………………...... 765

4.4 Transmission electron microscope ............................................................. 765

4.5 Atomic force microscopy ……………………………………………........ 765

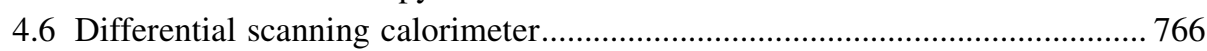

5. Bioavailability and bioaccessibility study of phenolic nanoconjugates ...................766

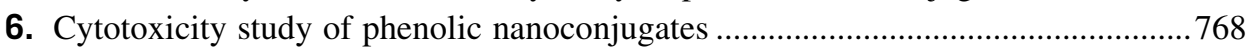

7. Application of phenolic nanoconjugates in the food industry ………………….......768

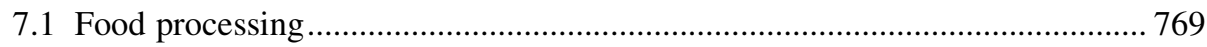

7.2 Food packaging ………………………………………………………. 770

8. Conclusion and future perspective..................................................................... 770

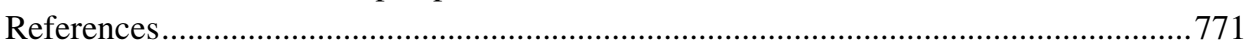

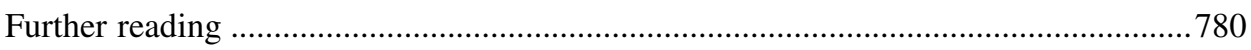

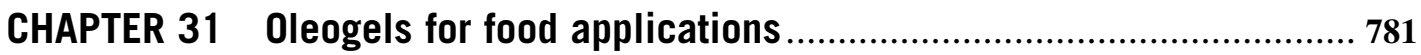

Mehmet Demirci, Chi-Ching Lee, Mustafa Çavuş and Muhammed Yusuf Çă̆lar

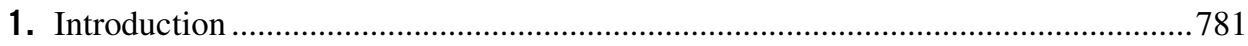

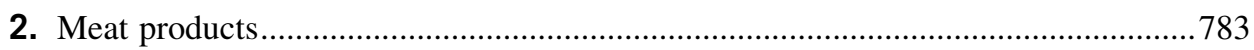

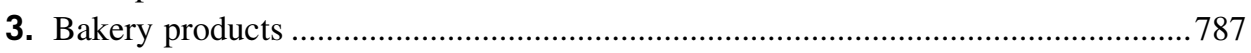

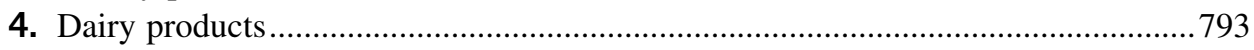

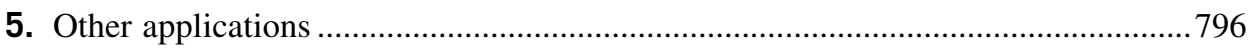

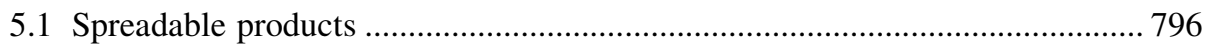




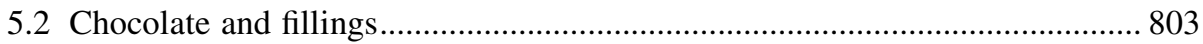

5.3 Usage of the oleogels as delivering material................................................... 804

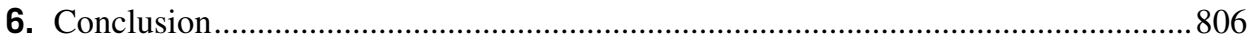

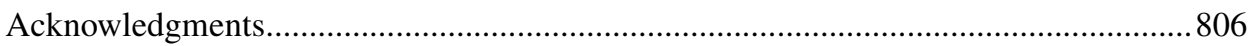

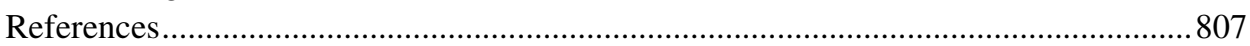

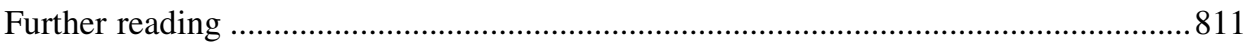

CHAPTER 32 CNT-tamarind gum-based solid-textured composite hydrogels for drug delivery applications.......................................813

Raj Deb, Dilshad Qureshi, Suraj Kumar Nayak, Vinay K. Singh,

Arfat Anis, Samrendra Maji, Doman Kim and Kunal Pal

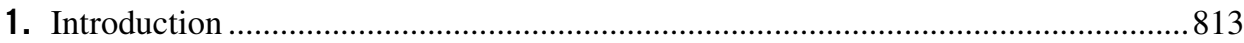

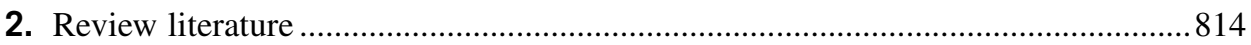

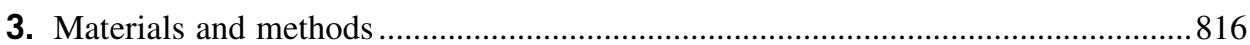

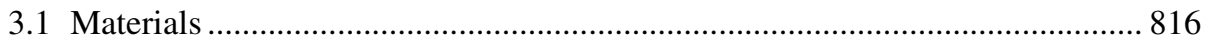

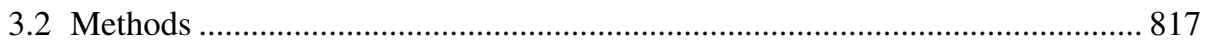

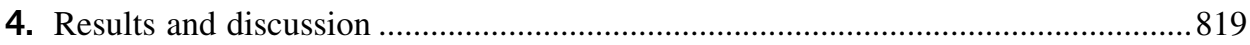

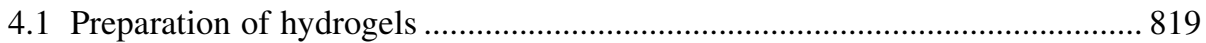

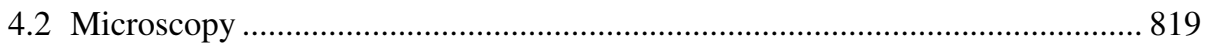

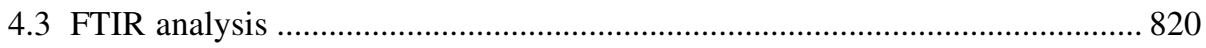

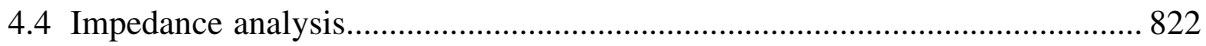

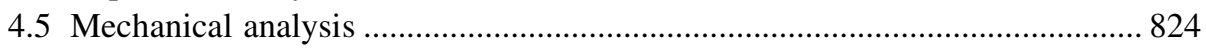

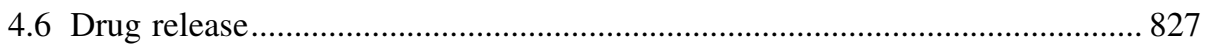

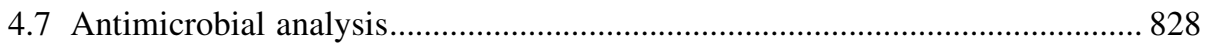

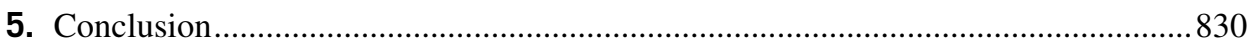

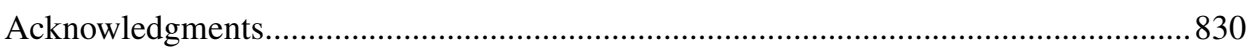

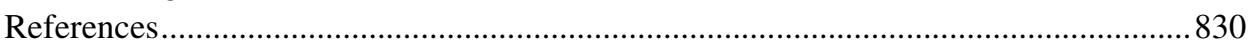

CHAPTER 33 Testicular tissue engineering: an emerging solution for

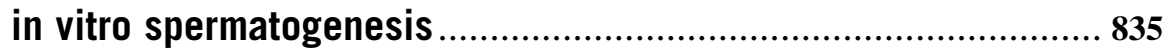

Rakesh Bhaskar and Mukesh Kumar Gupta

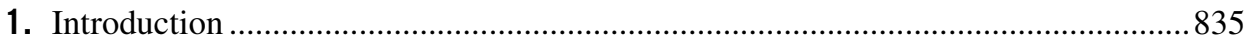

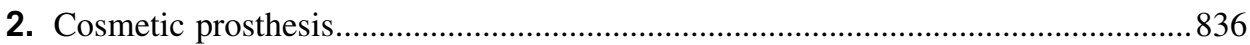

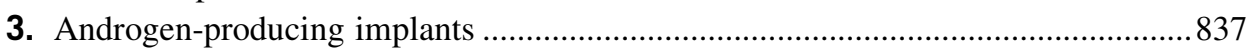

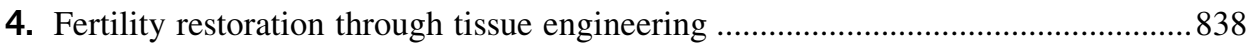

4.1 Types of cells for testicular tissue engineering ........................................... 838

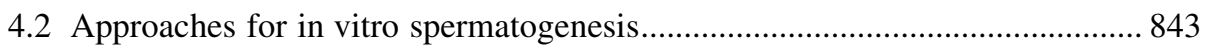

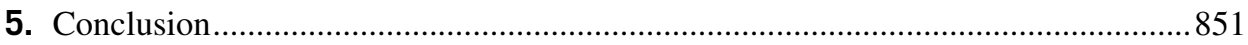

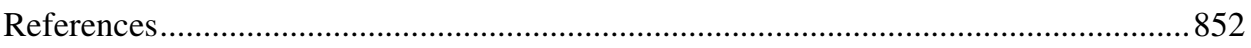




\section{CHAPTER 34 Enrichment of edible coatings and films with plant extracts} or essential oils for the preservation of fruits and vegetables.... 859

Alok Saxena, Loveleen Sharma and Tanushree Maity

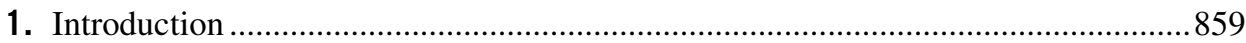

2. Development of edible films or coatings from various sources ............................... 860

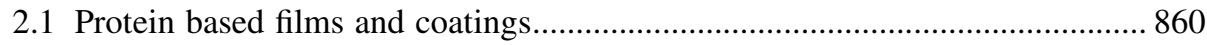

2.2 Polysaccharide based edible films and coatings ............................................ 862

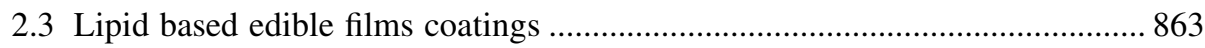

2.4 Composite coatings from protein and polysaccharides ................................... 863

3. Effect of edible coatings on various horticultural commodities ................................864

4. Use of plant extract, essential oils and antimicrobial agents in coatings and

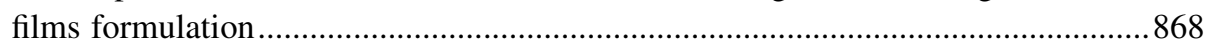

5. Effect of edible coatings with natural plant extracts, essential oil and

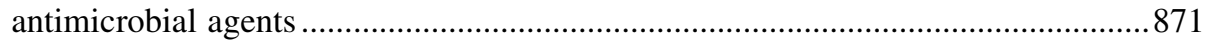

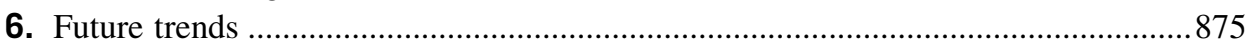

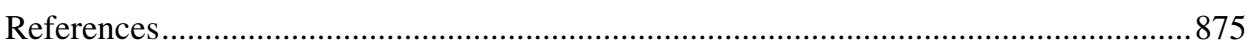

\section{CHAPTER 35 Collagen-based 3D structures-versatile, efficient materials} for biomedical applications ...................................................... 881 Geta David

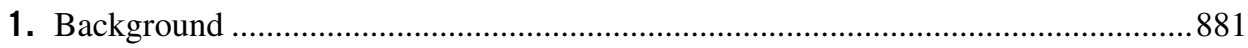

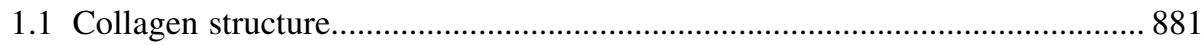

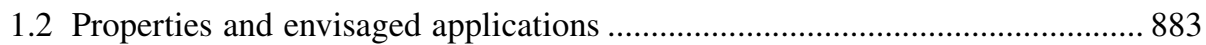

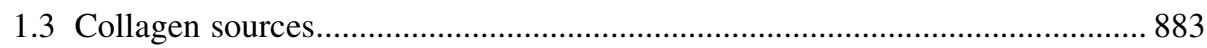

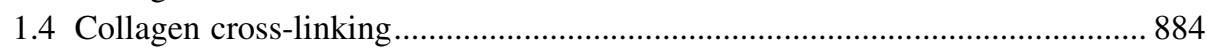

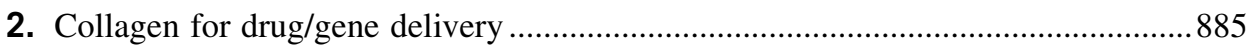

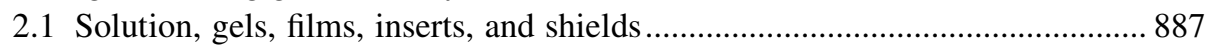

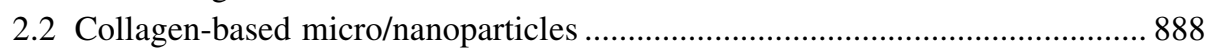

2.3 Hybrid and smart collagen-based drug delivery systems .............................. 890

3. Collagen-based formulations for scaffolding-From simple to complex, multifunctional systems —-Processing advances ....................................................... 891

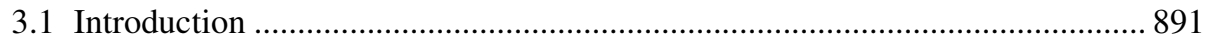

3.2 Collagen-based scaffold preparation methods-basic conventional

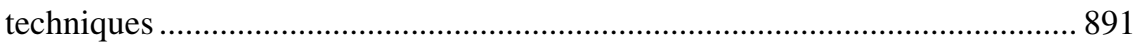

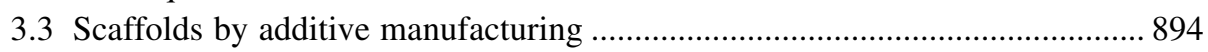

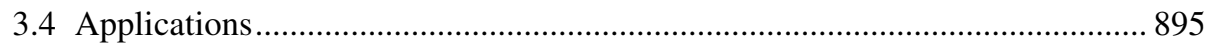

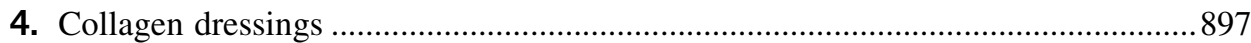

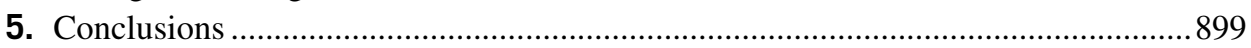

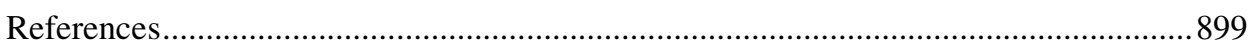

Index 


\section{Contributors}

\section{Saumya Agarwal}

Department of Food Process Engineering, NIT Rourkela, Rourkela, Odisha, India

\section{Jasim Ahmed}

Food and Nutrition Program, Environment and Life Sciences Research Center, Kuwait Institute for Scientific Research, Safat, Kuwait

\section{B. Amulyasai}

Department of Biotechnology and Medical Engineering, National Institute of Technology,

Rourkela, Odisha, India

\section{Anandharamakrishnan}

Computational Modeling and Nano Scale Processing Unit, Indian Institute of Food Processing Technology (IIFPT), Ministry of Food Processing Industries, Government of India, Thanjavur, India

\section{Arfat Anis}

Department of Chemical Engineering, King Saud University, Riyadh, Saudi Arabia

\section{Muhammad Arshad}

Department of Agricultural, Food and Nutritional Science, University of Alberta, Edmonton, AB, Canada

\section{Indranil Banerjee}

Department of Biotechnology and Medical Engineering, National Institute of Technology, Rourkela, Odisha, India

\section{Manav Bandhu Bera}

Department of Food Engineering and Technology, Sant Longowal Institute of Engineering and Technology, Longowal, Sangrur, Punjab, India

\section{Rakesh Bhaskar}

Department of Biotechnology and Medical Engineering, National Institute of Technology, Rourkela, Odisha, India

Pravin Bhattarai

Department of Biomedical Engineering, College of Engineering, Peking University, Beijing, Haidian, China

\section{Nisarani Bishoyi}

Department of Chemistry, NIT Rourkela, Rourkela, Odisha, India

\section{Prasanta Kumar Biswas}

Department of Food Technology and Biochemical Engineering, Jadavpur University, Kolkata, West Bengal, India

\section{Ragini G Bodade}

Department of Microbiology, Savitribai Phule Pune University, Pune, Maharashtra, India

\section{Anand G Bodade}

Department of Transfusion Medicine, Seth G S Medical College and KEM Hospital, Mumbai, Maharashtra, India 


\section{Subhadeep Bose}

Department of Food Technology and Biochemical Engineering, Jadavpur University, Kolkata, West Bengal, India

\section{Muhammed Yusuf Çağlar}

Istanbul Sabahattin Zaim University, Faculty of Engineering and Natural Sciences, Department of Food Engineering, İstanbul, Turkey

\section{Mustafa Çavuş}

Igdır University, Engineering Faculty, Department of Food Engineering, Iğdır, Turkey

\section{Jianshe Chen}

School of Food Science, University of Idaho, Moscow, ID, United States

\section{Harish Kumar Chopra}

Department of Chemistry, Sant Longowal Institute of Engineering and Technology, Longowal, Sangrur, Punjab, India

\section{Donghwa Chung}

Food Technology Major, Graduate School of International Agricultural Technology, Institute of Green Bio Science and Technology, Seoul National University, Pyeongchang, Gangwon, Republic of Korea

\section{Geta David}

Gh. Asachi Technical University of Iasi, Iasi, Romania

\section{Raj Deb}

Department of Biotechnology and Medical Engineering, National Institute of Technology, Rourkela, Odisha, India

\section{Mehmet Demirci}

Istanbul Sabahattin Zaim University, Faculty of Engineering and Natural Sciences, Department of Food Engineering, İstanbul, Turkey

\section{Win-Ping Deng}

School of Dentistry, College of Oral Medicine, Taipei Medical University, Taipei, Taiwan; Stem Cell Research Center, College of Oral Medicine, Taipei Medical University, Taipei, Taiwan; Graduate Institute of Basic Science, Fu Jen Catholic University, New Taipei City, Taiwan

\section{Chanda Vilas Dhumal}

Department of Food Process Engineering, NIT Rourkela, Rourkela, Odisha, India

\section{Navneet Kumar Dubey}

School of Dentistry, College of Oral Medicine, Taipei Medical University, Taipei, Taiwan; Stem Cell Research Center, College of Oral Medicine, Taipei Medical University, Taipei, Taiwan

\section{Rajni Dubey}

Institute of Food Science and Technology, National Taiwan University, Taipei, Taiwan

\section{Sayantani Dutta}

Computational Modeling and Nano Scale Processing Unit, Indian Institute of Food Processing Technology (IIFPT), Ministry of Food Processing Industries, Government of India, Thanjavur, India 


\section{Rimpi Foujdar}

Department of Food Engineering and Technology, Sant Longowal Institute of Engineering and Technology, Longowal, Sangrur, Punjab, India

\section{Advaita Ganguly}

Comprehensive Tissue Centre, UAH Transplant Services, Alberta Health Services, Edmonton, AB, Canada; Health Sciences Education and Research Commons, University of Alberta, Edmonton, AB, Canada

\section{Ann Mary George}

Department of Biomedical Engineering, Manipal Institute of Technology, Manipal Academy of Higher Education, Manipal, Karnataka, India

\section{Mukesh Kumar Gupta}

Department of Biotechnology and Medical Engineering, National Institute of Technology, Rourkela, Odisha, India

\section{Sadaf Hameed}

Department of Biomedical Engineering, College of Engineering, Peking University, Beijing, Haidian, China

\section{Thi Thanh Hanh Nguyen}

The Institute of Food Industrialization, Institutes of Green Bio Science \& Technology, Seoul National University, Pyeongchang-gun, Gangwon-do, Republic of Korea; Department of International Agricultural Technology \& Institute of Green BioScience and Technology, Seoul National University, Pyeongchang, Gangwon-do, Republic of Korea

\section{Md Saquib Hasnain}

Department of Pharmacy, Shri Venkateshwara University, Amroha, Uttar Pradesh, India

\section{Monjurul Hoque}

Department of Food Process Engineering, NIT Rourkela, Rourkela, Odisha, India

\section{Margaret 0. llomuanya}

Department of Pharmaceutics and Pharmaceutical Technology, Faculty of Pharmacy, University of Lagos, Surulere, Lagos, Nigeria

\section{John Jeslin}

Department of Biotechnology, St. Joseph's College of Engineering, Chennai, Tamil Nadu, India

\section{Juhui Jin}

Graduate School of International Agricultural Technology, Seoul National University, Pyeongchang-gun, Gangwon-do, Republic of Korea

\section{Padmaja Kar}

Department of Chemistry, NIT Rourkela, Rourkela, Odisha, India

\section{Hyo Jin Kim}

Graduate School of International Agricultural Technology, Seoul National University, Pyeongchang, Gwangwon-do, Republic of Korea; Institutes of Green Bio Science and Technology, Seoul National University, Pyeongchang, Gwangwon-do, Republic of Korea 


\section{Doman Kim}

Department of International Agricultural Technology \& Institutes of Green BioScience and Technology, Seoul National University, Pyeongchang, Gangwon-do, Republic of Korea; The Institute of Food Industrialization, Institutes of Green Bio Science \& Technology, Seoul National University, Pyeongchang-gun, Gangwon-do, Republic of Korea; Graduate School of International Agricultural Technology, Seoul National University, Pyeongchang-gun, Gangwondo, Republic of Korea

\section{Sanjeev Kumar}

Department of Biotechnology, Dr. Y.S. Parmar University of Horticulture and Forestry, Solan, Himachal Pradesh, India

\section{Chi-Ching Lee}

Istanbul Sabahattin Zaim University, Faculty of Engineering and Natural Sciences, Department of Food Engineering, İstanbul, Turkey

\section{Timothy Lee Turner}

Department of Microbiology-Immunology, Feinberg School of Medicine, Northwestern University, Chicago, IL, United States

\section{Mahalakshmi}

Computational Modeling and Nanoscale Processing Unit, Indian Institute of Food Processing Technology (IIFPT), Ministry of Food Processing Industries, Government of India, Thanjavur, Tamil Nadu, India

\section{Tanushree Maity}

Defence Research and Development Organization, DRDO Bhawan, Rajaji Marg, New Delhi, India

\section{Samrendra Maji}

SRM Research Institute, SRM Institute of Science and Technology, Kanchipuram, Tamil Nadu, India

\section{Kaustav Majumder}

Department of Food Science and Technology, University of Nebraska-Lincoln, Lincoln, NE, United States

\section{Maria Leena}

Computational Modeling and Nanoscale Processing Unit, Indian Institute of Food Processing Technology (IIFPT), Ministry of Food Processing Industries, Government of India, Thanjavur, Tamil Nadu, India

\section{Nupur Mohapatra}

Department of Food Process Engineering, NIT Rourkela, Rourkela, Odisha, India

\section{Jeyan A. Moses}

Computational Modeling and Nano Scale Processing Unit, Indian Institute of Food Processing Technology (IIFPT), Ministry of Food Processing Industries, Government of India, Thanjavur, India 


\section{Soma Mukherjee}

Department of Veterinary Medicine School, Mississippi State University, Mississippi State, MS, United States

\section{Amit Kumar Nayak}

Department of Pharmaceutics, Seemanta Institute of Pharmaceutical Sciences, Mayurbhanj, Odisha, India

\section{Suraj Kumar Nayak}

Department of Biotechnology and Medical Engineering, National Institute of Technology, Rourkela, Odisha, India

\section{Bhagyashree Padhan}

Department of Biotechnology and Medical Engineering, National Institute of Technology, Rourkela, Odisha, India

\section{Dilipkumar Pal}

Department of Pharmaceutical Sciences, Guru Ghasidas Vishwavidyalaya, Koni, Bilaspur, Chhattisgarh, India

\section{Kunal Pal}

Department of Biotechnology and Medical Engineering, National Institute of Technology, Rourkela, Odisha, India

\section{Ashok R. Patel}

Guangdong Technion Israel Institute of Technology, Shantou, China

\section{Rehan Ali Pradhan}

Department of Agricultural, Food and Nutritional Science, University of Alberta, Edmonton, AB, Canada

\section{Sushant Prajapati}

Department of Biotechnology and Medical Engineering, National Institute of Technology, Rourkela, Odisha, India

\section{Dilshad Qureshi}

Department of Biotechnology and Medical Engineering, National Institute of Technology, Rourkela, Odisha, India

\section{K.J. Rao}

Department of Biotechnology, Veltech University, Chennai, Tamil Nadu, India

\section{Sirsendu S. Ray}

Department of Biotechnology and Medical Engineering, National Institute of Technology, Rourkela, Odisha, India

\section{Sai Preetham Reddy Peddireddy}

Department of Biomedical Engineering, Manipal Institute of Technology, Manipal Academy of Higher Education, Manipal, Karnataka, India 
xxvi Contributors

\section{Fiona Concy Rodrigues}

Department of Biomedical Engineering, Manipal Institute of Technology, Manipal Academy of Higher Education, Manipal, Karnataka, India

\section{Sai S. Sagiri}

Department of Chemistry and Biochemistry, The City College of New York, New York, NY, United States

\section{Lanny Sapei}

Department of Chemical Engineering, University of Surabaya, Raya Kalirungkut, Surabaya, East Java, Indonesia

\section{Nandini Sarkar}

Department of Biotechnology and Medical Engineering, National Institute of Technology Rourkela, Rourkela, Odisha, India

\section{Preetam Sarkar}

Department of Food Process Engineering, NIT Rourkela, Rourkela, Odisha, India

\section{Angana Sarkar}

Department of Biotechnology and Medical Engineering, National Institute of Technology, Rourkela, Odisha, India

\section{Alok Saxena}

Amity Institute of Food Technology, Amity University Uttar Pradesh, Noida, Uttar Pradesh, India

\section{lis Septiana}

Graduate School of International Agricultural Technology, Seoul National University, Pyeongchang-gun, Gangwon-do, Republic of Korea

\section{Kumakshi Sharma}

Health, Safety and Environment Branch, National Research Council Canada, Edmonton, AB, Canada

\section{Loveleen Sharma}

Amity Institute of Food Technology, Amity University Uttar Pradesh, Noida, Uttar Pradesh, India

\section{Abhinay Kumar Singh}

School of Dentistry, College of Oral Medicine, Taipei Medical University, Taipei, Taiwan; Stem Cell Research Center, College of Oral Medicine, Taipei Medical University, Taipei, Taiwan

\section{Vinay K. Singh}

Research and Development, Intas Pharmaceuticals Limited, Ahmedabad-Gujarat, India

\section{Agustin Wulan Suci Dharmayanti}

University of Jember, Jember, East Java, Indonesia

\section{Yumewo Suzuki}

DSP Gokyo Food \& Chemical Co., Ltd., Osaka, Japan

\section{Irshaan Syed}

Department of Food Process Engineering, NIT Rourkela, Rourkela, Odisha, India 


\section{Akira Tabuchi}

DSP Gokyo Food \& Chemical Co., Ltd., Osaka, Japan

\section{Goutam Thakur}

Department of Biomedical Engineering, Manipal Institute of Technology, Manipal Academy of Higher Education, Manipal, Karnataka, India

\section{Aman Ullah}

Department of Agricultural, Food and Nutritional Science, University of Alberta, Edmonton, AB, Canada

\section{Rituja Upadhyay}

School of Food Science and Biotechnology, Zhejiang Gongshang University, Hangzhou, China;

School of Food Science, University of Idaho, Moscow, ID, United States

\section{Madan L. Verma}

Centre for Chemistry and Biotechnology, Deakin University, Geelong, VIC, Australia

\section{Lei Wang}

Department of Food Science and Technology, University of Nebraska-Lincoln, Lincoln, NE, United States

\section{Varsha Wankhade}

Department of Zoology, Savitribai Phule Pune University, Pune, Maharashtra, India

\section{Hiroyuki Yamada}

DSP Gokyo Food \& Chemical Co., Ltd., Osaka, Japan

\section{Kazuhiko Yamatoya}

DSP Gokyo Food \& Chemical Co., Ltd., Osaka, Japan

\section{Yue Zhang}

College of Food \& Biology Engineering, Zhejiang Gongshang University, Hangzhou, Zhejiang, China; Department of Food Science and Technology, University of Nebraska-Lincoln, Lincoln, NE, United States

\section{Muhammad Zubair}

Department of Agricultural, Food and Nutritional Science, University of Alberta, Edmonton, AB, Canada 


\section{BIOPOLYMER-BASED FORMULATIONS}

\section{BIOMEDICAL AND FOOD APPLICATIONS}

\section{EDITED BY: KUNAL PAL, INDRANIL BANERJEE, PREETAM SARKAR, DOMAN KIM, WIN-PING DENG, NAVNEET KUMAR DUBEY AND KAUSTAV MAJUMDER}

\section{Key Features}

- Provides in-depth coverage of methods for the characterization of the physical properties of biopolymeric architectures

- Supports a range of novel applications, including scaffolds, implant coatings, drug delivery, and nutraceutical encapsulation systems

- Includes the use of experimental data and mathematical modeling, thus enabling the reader to analyze and compare the properties of different polymeric gels

Biopolymer-Based Formulations: Biomedical and Food Applications presents the latest advances in the synthesis and characterization of advanced biopolymeric formulations and their state-of-the-art applications across biomedicine and food science. The book covers fundamentals, applications, future trends, and environmental, ethical, and medical considerations, and biopolymeric architectures are organized into nano-, micro-, and macroscales. The final section of the book focuses on novel applications and recent developments.

This book is an essential resource for researchers, scientists, and advanced students in biopolymer science, polymer science, polymer chemistry, polymer composites, plastics engineering, biomaterials, materials science, biomedical engineering, and more. It is also of interest to R\&D professionals, scientists, and engineers across the plastics, food, biomedical, and pharmaceutical industries.

\section{ABOUT THE EDITORS}

Prof. Kunal Pal is Professor-in-Charge of Medical Electronics and Instrumentation Laboratory in the Department of Biotechnology and Medical Engineering, National Institute of technology, Rourkela, India.

Prof. Indranil Banerjee is Assistant Professor in the Department of Biotechnology and Medical Engineering at National Institute of Technology, Rourkela.

Prof. Preetam Sarkar is Assistant Professor of Food Sciences at National Institute of Technology, Rourkela, India.

Prof. Doman Kim is a Professor in the Department of International Agricultural Technology at Seoul National University. He also serves as a Director of the Institute of Food Industrialization, Institutes of Green Bio Science \& Technology, SNU, and holds the post of Adjunct Professor at Audubon Sugar Institute, LSU-AgCenter, St. Gabriel, USA.

Prof. Win-Ping Deng is Deputy Dean and Distinguished University Professor at the College of Oral Medicine, Taipei Medical University (TMU), Taiwan, and is also currently serving as a Chair Professor at Fu Jen Catholic University, Taiwan.

Dr. Navneet Kumar Dubey is a researcher at the Stem Cell Research Center, College of Oral Medicine, Taipei Medical University, Taiwan. He is also an adjunct faculty member of Ceramics and Biomaterials Research Group, Advanced Institute of Materials Science, Ton Duc Thang University, Ho Chi Minh City, Vietnam.

Prof. Kaustav Majumder is Assistant Professor at the Department of Food Science, University of Nebraska, Lincoln, USA.

\section{Related Titles}

Sin \& Tueen, Polylactic Acid, Second Edition, William Andrew, 9780128144725

Aguilar \& Román (eds.), Smart Polymers and their Applications, Second Edition, Elsevier, 9780081024164 Huang, Fu \& Gan (eds.), Lignin Chemistry and Applications, Elsevier, 9780128139417

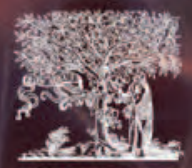

ELSEVIER 